Kennesaw State University

DigitalCommons@Kennesaw State University

Faculty Publications

$1-24-2017$

\title{
Searching for Illicit Behavior through Changes in Productivity: The Case of Roger Clemens and Performance-enhancing Drugs
}

John Charles Bradbury

Kennesaw State University

Follow this and additional works at: http://digitalcommons.kennesaw.edu/facpubs

Part of the Economics Commons, and the Finance and Financial Management Commons

\section{Recommended Citation}

Bradbury, John Charles, "Searching for Illicit Behavior through Changes in Productivity: The Case of Roger Clemens and Performance-enhancing Drugs" (2017). Faculty Publications. 4012.

http://digitalcommons.kennesaw.edu/facpubs/4012 


\title{
Searching for Illicit Behavior through Changes in Productivity: The Case of Roger Clemens and Performance-Enhancing Drugs
}

John Charles Bradbury ${ }^{1}$

\begin{abstract}
Major League Baseball pitcher Roger Clemens has been accused of using performanceenhancing drugs to boost his performance. If Clemens used ergogenic aids consistent with the accusations of use, then unusual changes in productivity may be evident in his performance record. Two previous studies have examined Clemens's career and reached conflicting conclusions: Bradlow et al. (2008) declares Clemens's career to be "atypical" while Albert (2009) finds Clemens's productivity to be unusually strong but similar to other pitchers who have not been linked with performance-enhancing drugs. This study examines Clemens's performance at times of alleged use and over his career and finds that changes in productivity are not indicative of performance-enhancing drug use.
\end{abstract}

Draft: January 24, 2017

${ }^{1}$ Contact: Department of Economics, Finance, and Quantitative Analysis, Kennesaw State University, 560 Parliament Garden Way NE, Kennesaw, Georgia 30144, jcbradbury@,kennesaw.edu. Disclosure of Interest: Author previously served as a paid consultant to attorneys representing Roger Clemens relating to legal matters regarding the subject of this paper. The author received no compensation for producing this manuscript, and the manuscript was not vetted by, or written at the direction of, any representative of Roger Clemens or associated legal counsel. The views expressed in the paper are solely those of the author. 


\section{Introduction}

In 2007, former United States Senator George Mitchell released a report to the Commissioner of Baseball on his investigation of alleged performance-enhancing drug use by Major League Baseball players (Mitchell 2007). The "Mitchell Report" (as it is commonly known) included accusations of steroid and human growth hormone use by renowned Major League Baseball pitcher Roger Clemens. Clemens denied the accusations under oath before Congress, and he was indicted on charges of perjury, making false statements, and obstruction of Congress. However, Clemens was acquitted of these charges and remains adamant about his innocence.

Despite his acquittal, Clemens is largely viewed as guilty of using performance-enhancing drugs by the public. A 2008 Gallup Poll revealed that 57percent of baseball fans believed Clemens lied in his testimony to Congress. Though he was one of most dominant pitchers in the history of baseball, since he became eligible for enshrinement in Baseball's Hall of Fame in 2013, he has averaged approximately 40 percent of the vote, well short of the 75 percent required for induction. Suspicion regarding his use remains largely because the sustained excellent performance he experienced throughout his career.

The fact that the substances that Clemens is accused of taking may be ergogenic means his historical performance record may offer insights as to whether or not he used performanceenhancing drugs at different points in his career. Economists have used sports data to identify corrupt behavior that is often difficult to detect. Duggan and Levitt (2002) use match data to identify match-fixing in sumo wrestling. Gould and Kaplan (2011 and 2013) and Bradbury (2013) use baseball to examine the spread of performance-enhancing drugs through peer effects in baseball, reaching different conclusions. Furthermore, this analysis provides a template for forensic statistical analysis of athletic performance for identifying performance-enhancing drug use.

Two previous studies have examined changes in Clemens's productivity in search of odd deviations or patterns in career performance that might indicate his performances could not be produced naturally and reach somewhat conflicting conclusions. Bradlow et al. (2008) identifies aspects of Clemens's career productivity that the authors identify as "atypical," while Albert (2009) finds that though Clemens's late-career performance to be unusually strong, it was similar to several pitchers who have not been linked with performance-enhancing drugs.

In this paper, I examine performance data from Clemens's career to identify evidence of performance-enhancing drug use through changes in performance. I examine performance changes at the times of specific allegations detailed in the Mitchell Report, as well as trends in productivity over his career. The findings indicate that at specific times, when he has been accused of using drugs, Clemens's productivity is not indicative of use. Clemens's overall performance trend is similar to other pitchers who excelled over their careers. Also, Clemens's perceived mid-career "twilight" resurgence is exaggerated and not out of line with his previous 
performances. Thus, contrary to popular perception, Roger Clemens's sustained productivity as a major-league pitcher was not abnormal and does not provide supporting evidence to existing allegations of performance-enhancing drug use.

I begin with justification for selecting the main performance metrics used to evaluate Roger Clemens's productivity in Section 2. In Section 3, I analyze changes in performance surrounding specific time periods as alleged in the Mitchell Report. In Section 4, I examine Clemens's performance trend throughout his career as measured by several metrics. In Section 5, I compare Clemens's career to the careers of several similar pitchers. In Section 6, I examine Clemens's mid-career resurgence. In Section 7, I conclude the analysis with a discussion of the findings.

\section{Measuring the Productivity of Baseball Pitchers}

In order to evaluate changes in performance it is important determine which metrics are best for identifying performance-enhancing drug use. Bradbury (2010) provides three criteria for evaluating the usefulness of a sports performance metric: how well it correlates with success, how much its variance reflects differences in talent-based performance versus random fluctuations, and whether or not the inferences drawn from the metric fit with the standard understanding of what constitutes good performance.

For pitchers, strikeouts, walks, and home runs are three metrics that strongly correlate with run prevention (more strikeouts, fewer walks, and fewer home runs are associated with fewer runs allowed), reflect the talent ability of pitches (pitchers tend to maintain these skills over time that improve and decline predictably over time, with age), and the correlations fit with our standard intuition of what constitutes good performance. A positive attribute of these metrics is that they record events that did not require the contribution of fielders-they are referred to as defenseindependent pitching statistics by McCracken (2001) — thus, they are a pure product of the pitcher performance unpolluted by fielder contributions. Bradbury (2007) confirms that these metrics appropriately meet these criteria for evaluating pitchers, and identifies problems with standard pitching metrics that rely too much on factors beyond pitchers' control, such as Wins, WHIP, and ERA.

The earned run average (ERA) is a measure of overall run-prevention ability. ERA credits pitchers with allowing runs, while removing fielding errors as determined by an official scorer. However, even after excluding errors, ERA is not as informative of a pitcher's talent-ability as the defense-independent pitching metrics. Though accounting for errors removes some fielding quality bias in overall run prevention, approximately 70 percent of all plate appearances end with a ball hit into play where fielders can produce, or fail to produce, an out. Therefore, random bounces of balls in play and overall fielder quality play a significant role in determining a pitcher's ERA. 
This is not to say that ERA is a useless metric. To the contrary, as an overall performance metric ERA is superior to WHIP ([Walks + Hits]/Innings Pitched), the primary performance metric used in previous analyses of Clemens's performance, because it captures pitchers' performance ability in more than just two areas. Hits are heavily-determined by factors beyond a pitcher's control, and walks are not likely to be much affected by performance-enhancing drugs. Still, it is important to acknowledge ERA's weaknesses in measuring individual performance. It also points to the importance of analyzing how outside factors (such as defense, playing environment, etc.) may have affected Clemens's on-field performance.

It is also important to adjust for changes in the performance environment over time. Figure 1 maps the changes in league-wide performance in the four main metrics used in this analysis, and demonstrates that there was much change over the course of Clemens's career. ${ }^{2}$ When Clemens entered the league in 1984, offense was much lower than it was by the time he exited the game in 2007. ERA and home runs increased over this span; walks rose and then declined; and strikeouts increased. Roger Clemens's raw performance statistics, uncorrected for the change in playing environment, provide a misleading gage of how his performance changed over his career; therefore, I normalize his performance as the percent difference from his league's average in each year of analysis. ${ }^{3}$

Figure 1. Changes in MLB Performance (1984-2007)

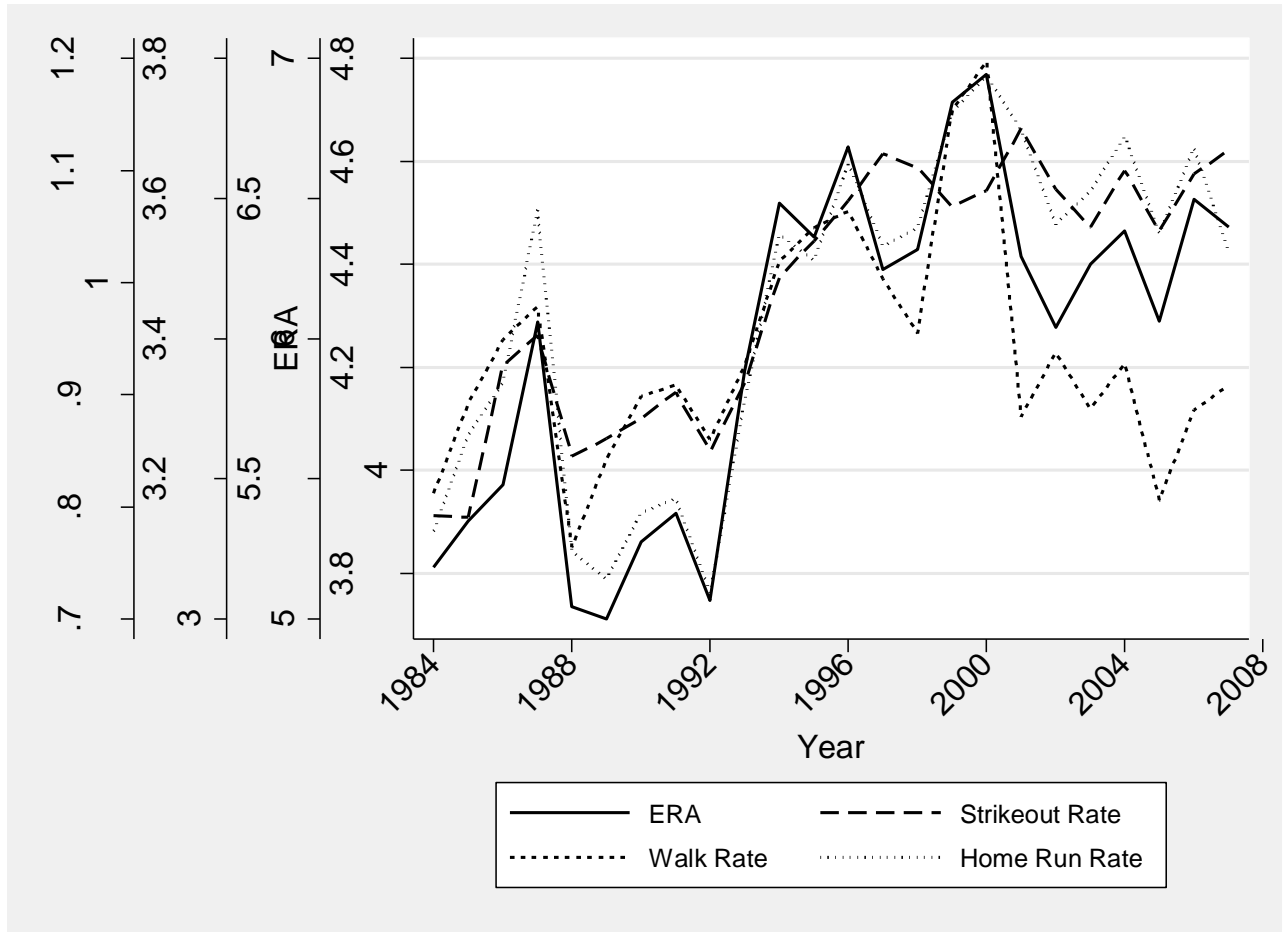

\footnotetext{
${ }^{2}$ In this paper, "per game" metrics are the overall performance divided by innings pitched and multiplied by nine, to be consistent with ERA.

${ }^{3}$ I also normalized using a $z$-score, but this method did not yield conclusions different from those presented in this paper. Z-score normalized graphs are available from the author upon request.
} 
In addition to relying on metrics that measure individual contributions to productivity through winning, these metrics should capture performance improvements produced by performanceenhancing drugs. Anabolic steroids have been demonstrated to be an effective ergogenic agent that can increase muscle mass and strength that should predictably affect baseball player performance. If pitchers gain an edge from steroids, then steroid use will likely result in more pitches thrown in the strike zone, resulting in more strikeouts and fewer walks, and possibly fewer home runs. Tobin (2008) notes that though ergogenic gains from anabolic steroids are asymmetrically beneficial to hitters, the effects may reduce ERA by up to 0.5 runs per game for pitchers. While there is strong evidence that anabolic steroids improve athletic performance, the bulk of scientific studies do not find ergogenic effects from human growth hormone, which Clemens is alleged to have used in 2000 (Stacy et al. 2004).

\section{Performance Surrounding the Times of Specific Allegations}

The Mitchell Report alleges that Roger Clemens used performance-enhancing drugs at three specific instances during his career. These time periods provide the opportunity to examine how Clemens was pitching at the alleged times of use, to observe the motivation for use, as well as evidence of improved performance. I examine each season in order.

\section{a. 1998}

During the 1998 season, while playing for the Toronto Blue Jays, Clemens was accused of seeking out and using anabolic steroids during a road trip stop against the Florida Marlins, and continuing use throughout the remainder of the season. If Clemens felt that he needed to use steroids to enhance his performance, then one might expect to see his performance early in the 1998 season deviating from his previous excellent performance. Using his June 8 start against the Florida Marlins as a reference point, examining Clemens's performance as compared to his recent past performance may shed some light on any potential motivation to use steroids.

Table 1 lists Clemens's performances through the first 13 games of the season for 1998 and the preceding five seasons. During the first 13 games of 1998, Clemens was striking out 9.18 batters and giving up 0.32 home runs per game. These performances were 44-percent and 71-percent better than the league averages in these respective areas. The area where Clemens struggled the most was in walking batters: he was walking 4.32 batters a game, which was 26-percent worse than the league average. Overall, his ERA was 3.27, which was 30-percent below the 1998 American League average ERA of 4.66. Clemens would ultimately lead the AL with an ERA of 2.65, but his June 8 ERA would have been good enough to finish with the league's third-best ERA in 1998. His ERA of 3.27 was similar to his ERAs for the first 13 games and seasonal averages of his previous five seasons. He was striking out batters at a higher rate and giving up home runs at a lower rate than in previous seasons. Where his pitching was much worse was in terms of walks: he was walking approximately one more batter a game than he had in his previous five seasons. 
Table 1. Roger Clemens's First 13 Game Performances (1993-1998)

\begin{tabular}{|c|c|c|c|c|c|c|c|c|c|}
\hline \multirow[b]{2}{*}{ Year } & \multicolumn{2}{|c|}{ ERA } & \multicolumn{2}{|c|}{ BB9 } & \multicolumn{2}{|c|}{ SO9 } & \multicolumn{2}{|c|}{ HR9 } & \multirow{2}{*}{$\begin{array}{c}\text { Pitches Thrown } \\
\text { (median) }\end{array}$} \\
\hline & Raw & $\% \operatorname{Lg}$ Avg & Raw & $\% \operatorname{Lg}$ Avg & Raw & $\% \operatorname{Lg}$ Avg & Raw & $\% \operatorname{Lg} A v g$ & \\
\hline 1998 & 3.27 & $-30 \%$ & 4.32 & $26 \%$ & 9.18 & $44 \%$ & 0.32 & $-71 \%$ & 115 \\
\hline 1997 & 1.94 & $-58 \%$ & 2.67 & $-24 \%$ & 8.57 & $33 \%$ & 0.37 & $-66 \%$ & 121 \\
\hline 1996 & 4.19 & $-16 \%$ & 3.99 & $5 \%$ & 9.82 & $57 \%$ & 0.92 & $-24 \%$ & 123 \\
\hline 1995 & 5.21 & $10 \%$ & 4.12 & $9 \%$ & 8.23 & $36 \%$ & 1.45 & $34 \%$ & 99 \\
\hline 1994 & 2.45 & $-49 \%$ & 3.34 & $-11 \%$ & 9.62 & $58 \%$ & 0.59 & $-47 \%$ & 116 \\
\hline 1993 & 3.26 & $-25 \%$ & 2.78 & $-22 \%$ & 8.33 & $45 \%$ & 0.77 & $-17 \%$ & 114 \\
\hline \multicolumn{10}{|c|}{ First 13 Games } \\
\hline 1993-1997 & 3.41 & & 3.38 & & 8.91 & & 0.82 & & 115 \\
\hline \multicolumn{10}{|c|}{ Whole Seasons } \\
\hline 1993-1997 & 3.43 & & 3.40 & & 8.87 & & 0.71 & & 120 \\
\hline
\end{tabular}

While it is impossible to know what might motivate a player to start using performanceenhancing drugs, if one assumes that diminished performance might motivate a player to seek an ergogenic aid, the first 13 games of Roger Clemens's 1998 season do not appear to be all too different from his recent past performance. Even when compared to his stellar 1997 season, though his ERA was higher on June 8, 1998 than it was after the first 13 games of 1997, he was striking out batters at a higher rate and allowing a comparable rate of home runs. Where he did not excel in early-1998 was in walks: he walked 1.65 more batters a game than he did in 1997. Steroids would seem to be a nonobvious avenue for seeking and an improvement in walk prevention. His overall performance was also well above league average.

As for how his performance changed after the alleged doping began, Clemens improved his performance in all areas, except home runs, but the performances were not statistically different from how he performed during the first 13 games. Table 2 reports his average performance before and after, as well as the t-statistics and associated p-values from a t-test of means. ${ }^{4}$

Table 2. Performance During and After First-13 Games of Season (1998)

\begin{tabular}{|lcccc|}
\hline Performance & Before & After & T-Statistic & P-value \\
\hline ERA & 3.27 & 2.29 & 0.76 & 0.45 \\
K9 & 9.18 & 11.09 & 1.42 & 0.17 \\
BB9 & 4.32 & 2.83 & 1.57 & 0.13 \\
HR9 & 0.32 & 0.48 & 0.55 & 0.58 \\
\hline
\end{tabular}

b. 2000

During the 2000 season, Clemens was accused of seeking performance-enhancing drugs around the middle of season, and subsequently receiving four-to-six injections of anabolic steroids and

${ }_{4}$ T-test of per-game performance. The t-test of means excludes the second game of the season, which Clemens exited without recording an out due to an injury. Alternate estimates that assumed production with one out did not yield statistically significant results. 
human growth hormone. I compare Clemens's performances by halves of the season, denoted by performances before and after the All-Star Break. His 1999 performance statistics and average performances from the preceding five seasons (1995-1999) are included in Table 3 for comparison.

Table 3. Roger Clemens Performances by Half-Seasons (1995-1999)

\begin{tabular}{|c|c|c|c|c|}
\hline & ERA & K9 & BB9 & HR9 \\
\hline First Half & 4.33 & 8.47 & 3.76 & 1.22 \\
\hline Second Half & 3.15 & 8.12 & 3.64 & 1.08 \\
\hline T-Statistic & 0.68 & 0.22 & 0.89 & 0.13 \\
\hline P-Value & 0.50 & 0.83 & 0.38 & 0.90 \\
\hline 1999 & 4.60 & 7.82 & 4.32 & 0.96 \\
\hline 1995-1999 & 3.42 & 9.24 & 3.56 & 0.67 \\
\hline 2000 League Average & 4.92 & 6.27 & 3.75 & 1.20 \\
\hline Clemens vs. League Average (1995-1999) & $-29 \%$ & $47 \%$ & $-3 \%$ & $-41 \%$ \\
\hline Clemens vs. League Average (2000) & $-12 \%$ & $35 \%$ & $0 \%$ & $2 \%$ \\
\hline
\end{tabular}

Clemens's first-half ERA, strikeout rate, and walk rate were all superior to his 1999 season. His strikeout rate and ERA were better than league average, while his walk and home run rates were approximately league average. Compared to his performances in the previous five seasons, his first-half performances were slightly worse in all areas. The area where he performed the worst was home run prevention. In the second half, his ERA declined; however, his performance components were similar to his first half, which indicates that the change was more attributable to outside factors (e.g., fielding defense, randomness, etc.) than improved pitching by Clemens. A t-test of sample means in the first-half and second-half of the season finds the differences in performance were not statistically significant.

\section{c. 2001}

In 2001, Clemens was accused of using steroids on four or five occasions beginning in August. Table 4 reports Roger Clemens's performance up until August 2001, when the alleged interest in taking steroids supposedly began. At the end of July 2001, Clemens was pitching above his performance for the previous year and pitching well above league average — so well that he would ultimately win the AL Cy Young Award for the season. Because the alleged use occurred so late in the year, it would be difficult to identify any ergogenic effect during the remaining two months of the season. However, Clemens's August-through-October results are similar to his preceding performance. If anything, he pitched slightly worse during the remainder of the season. 
Table 4. Roger Clemens's Performance (2001)

\begin{tabular}{|c|c|c|c|c|}
\hline & ERA & K9 & BB9 & HR9 \\
\hline April-July & 3.58 & 8.92 & 2.79 & 0.91 \\
\hline August-October & 3.38 & 8.25 & 3.25 & 0.50 \\
\hline 2000 & 3.70 & 8.28 & 3.70 & 1.15 \\
\hline $1996-2000$ & 3.33 & 9.20 & 3.53 & 0.71 \\
\hline 2001 League Average & 4.48 & 6.44 & 3.24 & 1.11 \\
\hline Clemens vs. League Average (2001) & $-20 \%$ & $38 \%$ & $-14 \%$ & $-18 \%$ \\
\hline Clemens vs. League Average (1996-2000) & $-31 \%$ & $45 \%$ & $-4 \%$ & $-40 \%$ \\
\hline
\end{tabular}

Roger Clemens's performance during the 2001 season, up until the time when he allegedly sought the help of performance-enhancing drugs, was similar to his performance in preceding seasons. There does not appear to be diminished performance that might indicate underperformance and thus induce the player to seek an ergogenic aid.

d. Conclusion Regarding Specific Allegations

Roger Clemens's performances in 1998, 2000, and 2001 were no doubt excellent by major-league standards. In 1998 and 2001, Clemens would win the AL Cy Young Award and make the AllStar team. Yet, in terms of career excellence, they do not stand out as peculiar seasons in Roger Clemens's career that might indicate use of any ergogenic aid. 1998 could be considered one of Clemens's best seasons: he led the league in ERA, strikeouts, strikeout rate, and home run rate. However, he achieved all of these feats during other seasons of his career when drug use is not alleged. 1998 was one of seven seasons in which his earned run average (ERA) was at least 40percent better than the league average, and it was his fifth-best performance by this metric. He would have two superior seasons in 2005 and 2006 - four and five years after his last alleged administration of performance-enhancing drugs in 2001. In terms of ERA, 1998, 2000, and 2001 rank eighth, 15th, and 17th in his career performance. Also, his 1998 season was quite similar to his 1997 season, which occurred the season prior to when he was accused of first using performance-enhancing drugs.

There is also nothing in Roger Clemens's performance record during the years of accusation that indicate a dip in performance that might motivate performance-enhancing drug use or improved performance that resulted from ergogenic drug use. Clemens's performances before and after specific allegations of use are not statistically different from each other; thus, even if the allegations were true, he did not demonstrate a performance benefit from performanceenhancing drug use. While these findings may counter public perception, they should not be surprising as they concur with the jury verdict from Roger Clemens's perjury trial, which focused largely on the specific allegations included in the Mitchell Report. 


\section{The Career of Roger Clemens}

Roger Clemens had one of the most-distinguished pitching careers in baseball history. During his 24 years as a major-league player he won one MVP Award, seven Cy Young Awards, and made the All-Star team eleven times. His sustained excellence has raised suspicions that his performance may have been aided by performance-enhancing drugs. If Clemens performance did not vary according to the timeline of specific alleged use, then perhaps drug use can be identified at other times or through abnormally-sustained excellence over the course of his career. I begin the career analysis by examining Clemens's continuous performance in several relevant performance areas, and then I compare Clemens's career to the careers of other similar pitchers in the following section.

\section{a. Overall Performance}

Roger Clemens had a mean 3.12 ERA over his 24-year career. His ERA ranged from 1.87 in 2005 at age 42 to 4.60 in 1999 at age 36. Figure 2 plots his ERA over his career, and maps a Lowess trend. ${ }^{5}$ The three seasons during which Clemens is accused of using performanceenhancing drug (1998, 2000, and 2001) are marked with asterisks.

Figure 2. Roger Clemens's ERA by Age

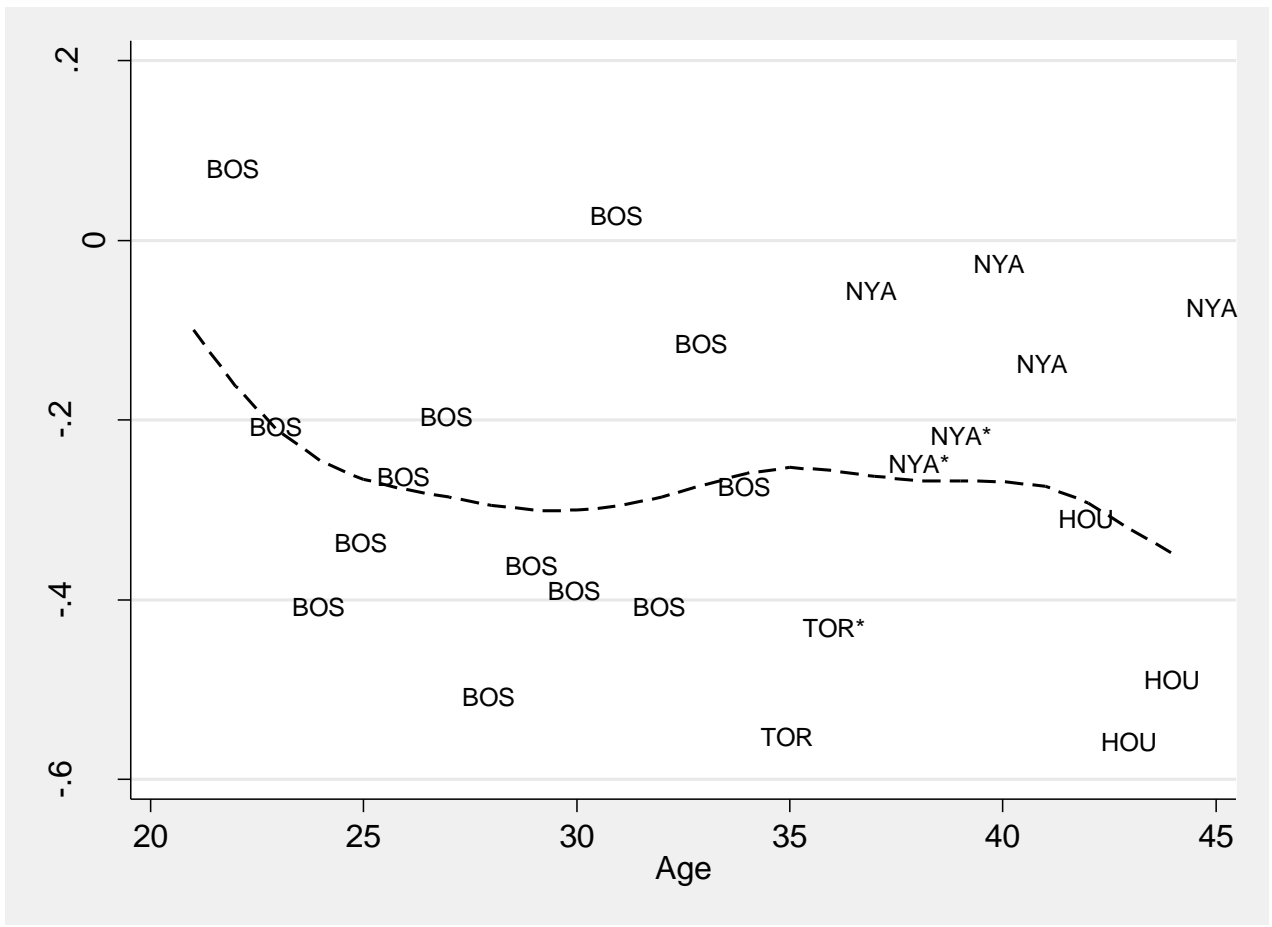

For all but two years of Clemens's career, his ERA was below the league average, with a mean of 27-percent better than league average. The estimated trend indicates that Clemens steadily

${ }^{5}$ I used the default Lowess weighting of Stata statistical software, which employs local weighting of 80 percent of the observations. 
improved through his 20 s before reaching a local peak in his late-20s and early-30s. Clemens had several excellent years in his mid-to-late-30s and 40s as well as some relatively poor years, which produced a trend estimate of slight improvement through the remainder of his $30 \mathrm{~s}$, and steeper improvement into his 40s. Bradbury (2009) estimates that pitchers tend to peak between the ages 27 and 32; thus, the trend shows improvement well into what is typically considered the decline phase of a pitcher's career. It is this atypical late-career excellence that has generated suspicion of performance-enhancing drug use by Clemens, in addition to the allegations detailed in the Mitchell Report.

\section{b. Specific Performance Metrics}

\section{i. $\quad$ Strikeouts}

The change of Clemens's strikeout rate over his career demonstrates why normalizing is important for this type of analysis. Figure 3 reports Clemens's normalized strikeout rate by age and includes non-normalized and normalized trends. Clemens's raw strikeout rate continued to rise into his mid-30s before entering a steep decline; however, this change in deceptive in terms of measuring Clemens's ability to produce strikeouts. As Figure 1 shows, during this period, strikeouts became more common in baseball. The rise in strikeouts in baseball masked Clemens's decline in this area relative to his peers: his normalized strikeout rate shows decline in this area at nearly a quadratic rate. This pattern is consistent with Bradbury (2009), which finds pitchers' normalized strikeout ability peaking at 24 and then declining.

Figure 3. Roger Clemens's Strikeouts by Age

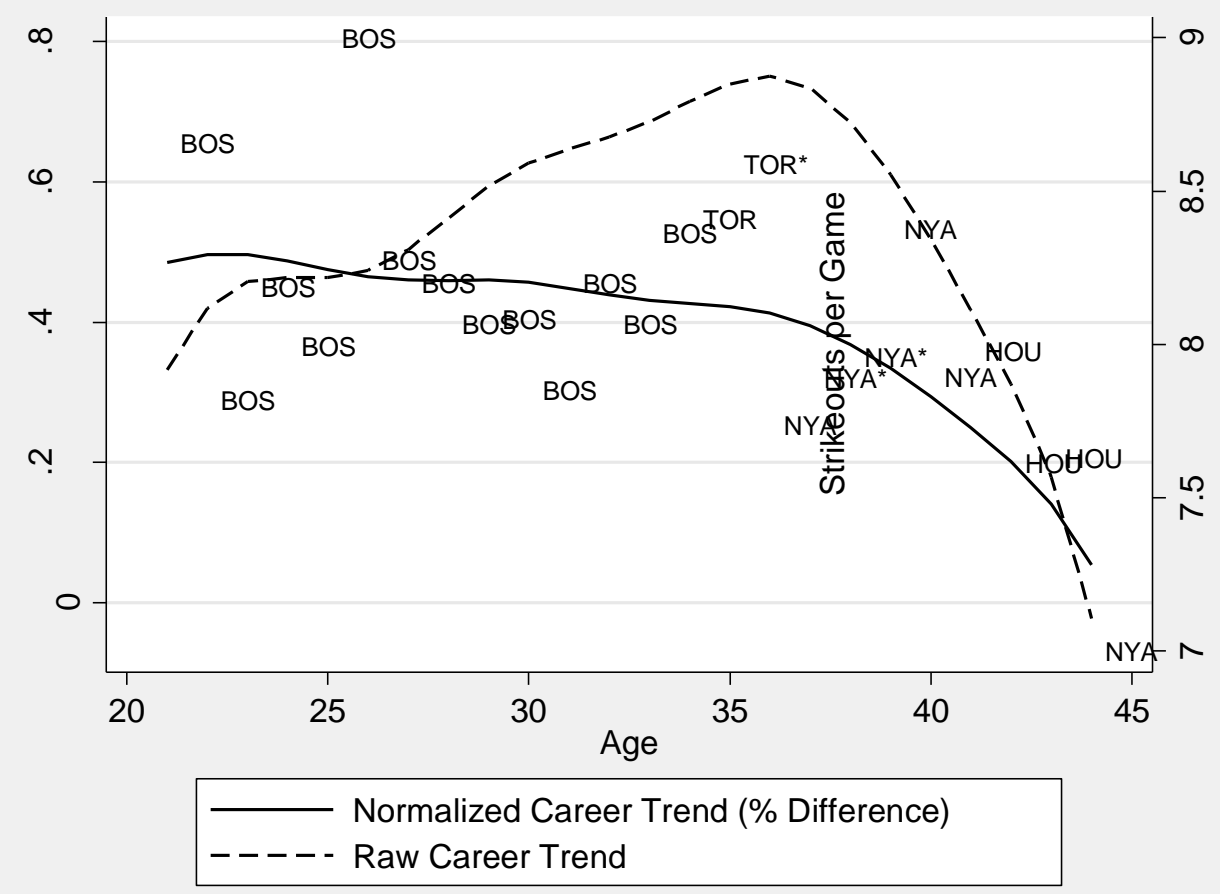


Clemens's 1998 performance in Toronto (-63 percent of the league average) -identified as a steroid-using year - was the third best strikeout performance of his career and his best performance after age 34 . However, his performance was not much different than his preceding years in 1996 (-53 percent) and 1997 (-55 percent). The other years in which he was accused of using drugs - 2000 (-32 percent) 2001 (-35 percent) — are similar to his late-career strikeout rates, and he had better post-2001 performances in 2002 (-53 percent) and 2004 (-36 percent). Thus, Clemens late-career success does not appear to be due to an abnormal improvement of his strikeout skill. These findings are consistent with findings reported in Bradlow et al. (2008).

\section{ii. Walks}

The oddest performance progression in Clemens's career is in how he walked batters. In general, pitchers tend to issue more walks at the beginning of their careers, improve into their early-30s, before permitting more walks as they age. Figure 4 shows Clemens's walk trend was upside down: he began by walking fewer batters, then allowed more walks, before improving again in his late-30s. One possible explanation for this reverse pattern is that ergogenic aids allowed Clemens to get away with more pitches in the strike zone, which resulted in fewer walks. However, if Clemens was able to get away with more pitches in the strike zone, then he should have experienced a corresponding increase in strikeouts, and Figure 3 shows a decline in Clemens's strikeout rate. Also, the years of accusation are not among Clemens's better seasons in preventing walks. Examination of Clemens's walk prevention performance indicates that his late-career improvement in walks played an important role in his late-career success in preventing runs; therefore, this is a curious trend that deserves closer scrutiny.

Figure 4. Roger Clemens's Walks by Age

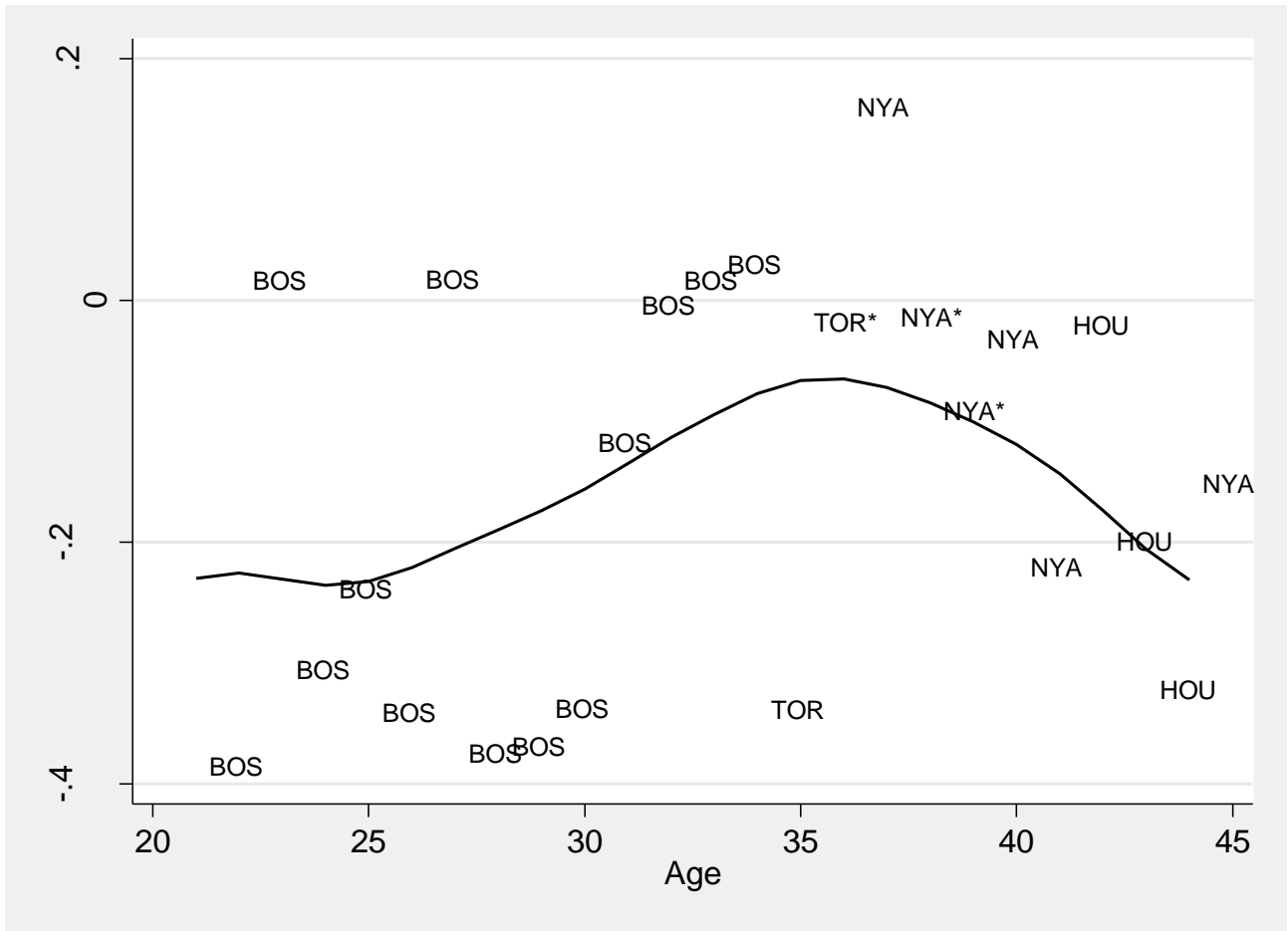


One possible explanation for the decline in walks is that Clemens compensated for his declining strikeout skills by changing his pitching strategy to reduce walks. Early in his career, Clemens was known as an overpowering, but erratic, fastball pitcher. In his younger days, he could be less concerned about walks because he could limit the damage of a walked batter with strikeouts. At his peak of walking batters at age 36 in 1999, Clemens had struck out twelve or more batters in a game 31 times over 16 seasons; Clemens would do so only four more times in his eight remaining seasons.

While this explanation involves post-hoc rationalization, there is evidence of a change in his approach to pitching that occurred. A report compiled by Clemens's agent (Hendricks et al. 2008) claims that Clemens developed a split-finger pitch in 1991, and mastered the pitch by the mid-1990s. A brief investigation reveals a change in Clemens's approach documented in the media long before performance-enhancing drug suspicions arose.

In his June 14, 2002 weekly scouting report, ESPN analyst Tom Candiotti identified a change in pitching strategy that included increased use of the split-finger fastball and how he pitched within the strike zone.

"Clemens still attacks with his fastball, but he has complemented his fastball by throwing a splitter to also go along with his slider...He has fallen in love with his splitter over the last five years. It is a very effective pitch for him as hitters recognize the fastball, but by the time they commit to their swing it is dipping out of the zone. He goes with this pitch a lot when he gets in trouble or needs a strikeout."

The mid-career change in Clemens's approach was also documented by several major-league hitters who faced him many times over his career in Mayo (2008).

Julio Franco played major-league baseball from 1982 to 2007 and faced Clemens 101 times in his career ranging from 1984 to 2007. Franco described facing Clemens in 1997 when he was 34 and with his first year with the Toronto Blue Jays.

"He was still throwing hard, but he got smarter. ...He lost 2 or 3 miles per hour on his fastball. His velocity was down. A smart pitcher like that has all this experience throwing fastballs 93, 94, he comes with the split-finger that made him a better pitcher than he was before. He knew he couldn't rely as much on his fastball, but he had a good curveball and now the split-finger he can throw either way to righties or lefties. That's what baseball is all about, readjusting" (p. 38).

\footnotetext{
${ }^{6}$ Candiotti, T. "Fastball, Splitter Key to Clemens' Success,” ESPN.com, June 14, 2002 (http://a.espncdn.com/mlb/columns/candiotti tom/1394841.html).
} 
Cal Ripken, Jr. played major-league baseball from 1981 to 2001 and faced Clemens 120 times from 1984 to 2001.

"Then when he developed that split-fingered changeup, that was a really good pitch for him, midway through his career. It's almost like he didn't need an off-speed pitch, per se, when he was blowing and throwing high in the strike zone. But when you do have one, it makes your fastball that much better" (pp. 68-69).

Chipper Jones played major-league baseball from 1993 to 2012 and faced Clemens 33 times from 1997 to 2006, also facing him in a minor-league game in 1993.

"But when he got that split and started learning how to throw it and use it, his career took off, again. Not only did he have an overpowering heater, he had the devastating split to put you away with, too" (p. 124).... The last couple of years, he's been a completely different pitcher. Obviously, he can still paint the 93, 94 on the outside corner, but he's developing a backdoor cutter, where if he falls behind in the count, he can paint that on the outside corner, which locks up a lot of hitters. Always in the back of your mind now, you better have that split.” (pp. 132-133)

A common theme within these comments is that it was apparent to scouts and his competitors that Clemens adopted new strategies as his career progressed. He was able to mix pitches effectively to keep hitters off balance and simply overpowering hitters with velocity became less a part of his repertoire as he aged. Most notably, he added a splitter, or split-finger, pitch that was effective at fooling batters, and later added a cutter or cut-fastball. Adair (1994) describes why a split-finger fastball behaves at it does and is an effective pitch for deceiving batters.

"The ordinary overhand fast ball is thrown so that the ball rolls off the first and middle fingers of the pitching hand-indeed, these fingers usually rest on the stitches to accentuate the grip and the spin. If the pitcher places the ball so that he holds its axis between his two widely split fingers at about the first joint, he will propel the ball almost as fast but with very little spin. Usually, the split-finger fast ball is not projected quite so efficiently as the regular backspinning fast ball and does not achieve the same velocity. With the same initial trajectory as the hopping 90 -mph fast ball directed across the letters, the 80 -mph split-finger fast ball reaches the plate about 16 inches lower and at the knees_-and about 7 feet behind the fast ball"' (p. 39).

Thus, the splitter is a pitch that a pitcher can learn by altering his grip on the ball: something a pitcher of any age can do with practice. The testimony of former competitors describes the action of Clemens's splitter as similar to what Adair (1994) describes. He also was able to use the new pitch strategically to confuse batters with a larger repertoire of similar-looking pitches they could expect from him. 
The improvement of Clemens's performance in walks was a significant factor in Clemens's later career success at preventing runs. If this improvement was aided by performance-enhancing drugs, through the increase in strength and power, walks is not the performance area in which ergogenic aids would help him improve. A better explanation for his late-career improvement in this area is that he changed in his strategic approach, which is well documented by many people close to the game.

This adjustment with age has been noted among other athletes. Past studies of aging have found evidence of athletes compensating for physical deterioration of skills with superior knowledge. For example, Baker et al. (2007) finds evidence of professional golfers becoming better at hitting fairways to compensate for diminished driving distance. In baseball, Bradbury (2009) finds that pitchers tend to reduce their walk rates as they age and peak at age 32, much later than the peaks for strikeout (24) and home run prevention (27). Because the improvement in walk prevention continues as strikeout and home run prevention abilities decline-so much so that ERA peaks at age 29-it is likely that pitchers are using their stock of knowledge to improve (e.g., better pitch placement within the strike zone, exploiting hitter and umpire tendencies, using strategy to set up batters, learning new pitches, etc.).

While improved knowledge may explain Clemens's late-career improvement, it does not explain why his career walk trend is an inverted-U rather than the U-shaped trend with an early-30s peak that is typical for pitchers. The oddity of Clemens performance in walks was a significant factor to Clemens's later career success. If success was aided by performance-enhancing drug, through the increase in strength and power, walks is not the performance area in which ergogenic aids would help him improve.

\section{iii. Home Runs}

Figure 5 shows Clemens's home runs allowed to be widely scattered, showing no obvious pattern at first glance. Similar to his ERA trend, the estimated shape of Clemens's career home runs allowed trend produces a slight decline through up until around age 30, when his home runs allowed increased slightly into his mid-30s, before leveling off, and then declining in his late-30s and early-40s. The high variance in home runs is not surprising given that home runs are rarer and naturally much more variable than strikeouts or walks (Bradbury 2008). Thus, even though Clemens may have had some late-career success in preventing home runs-especially during his time in Houston, which is discussed below - there does not appear to be a strong relationship between age and performance over his career. 
Figure 5. Roger Clemens's Home Runs Allowed by Age

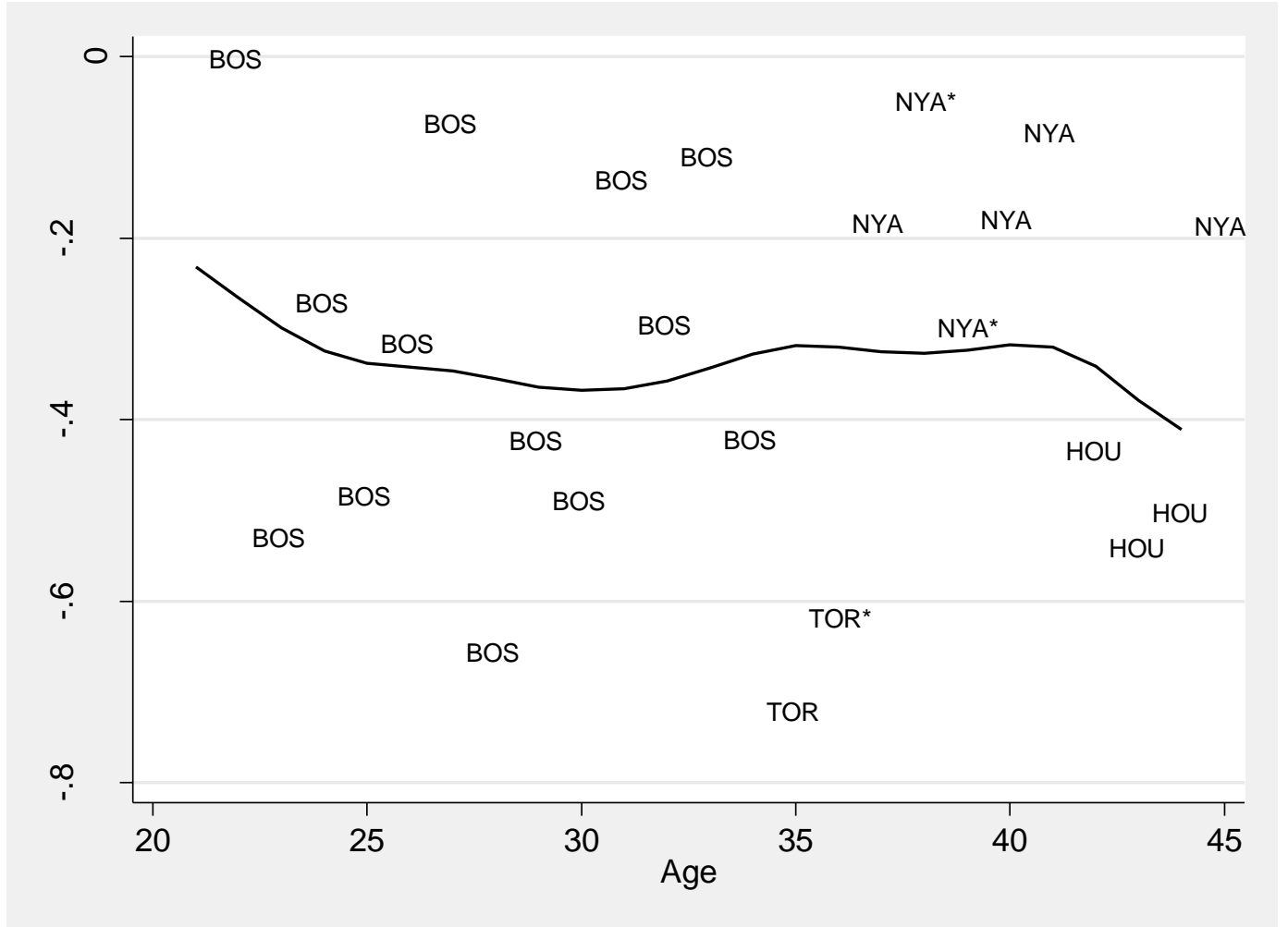

Of the three performance areas in which individual performance is meaningfully controlled by the pitcher: Clemens had a typical aging pattern in his strikeout rate; the walk trend is odd, but this is an area that is unlikely to be improved through performance-enhancing drugs; and home runs shows some late-career improvement, but home runs naturally fluctuate from year to year, and there is no obvious pattern in Clemens's home run performance trend that would indicate improvement that was the result of drug use. In the next section, I investigate outside factors that may have aided Clemens's performance.

\section{c. Outside Factors}

\section{i. $\quad$ Fielding}

Approximately 70 percent of all plate appearances result in a ball hit into the field of play, where it can fall for a hit or be turned into an out by fielders; thus, there is plenty of opportunity for the quality of the fielders to influence a pitcher's ERA. Figures 6 maps the Defense Efficiency (the percentage of balls into play that are turned into outs by fielders) of Clemens's teams over the course of his career. ${ }^{7}$ Unlike player performance metrics, which we expect to have a riseand-decline pattern over time with aging, defense has no predetermined shape. In Clemens's case, during his early career in, he experienced quite poor defenses playing behind him. $\mathrm{He}$ experienced above-average defense for only two years, and for most if his stint, Boston was near the bottom of the league in fielding.

${ }^{7}$ Defensive Efficiency reported by Baseball-Reference.com, various team pages. 
Figure 6. Roger Clemens's Team Defense by Age

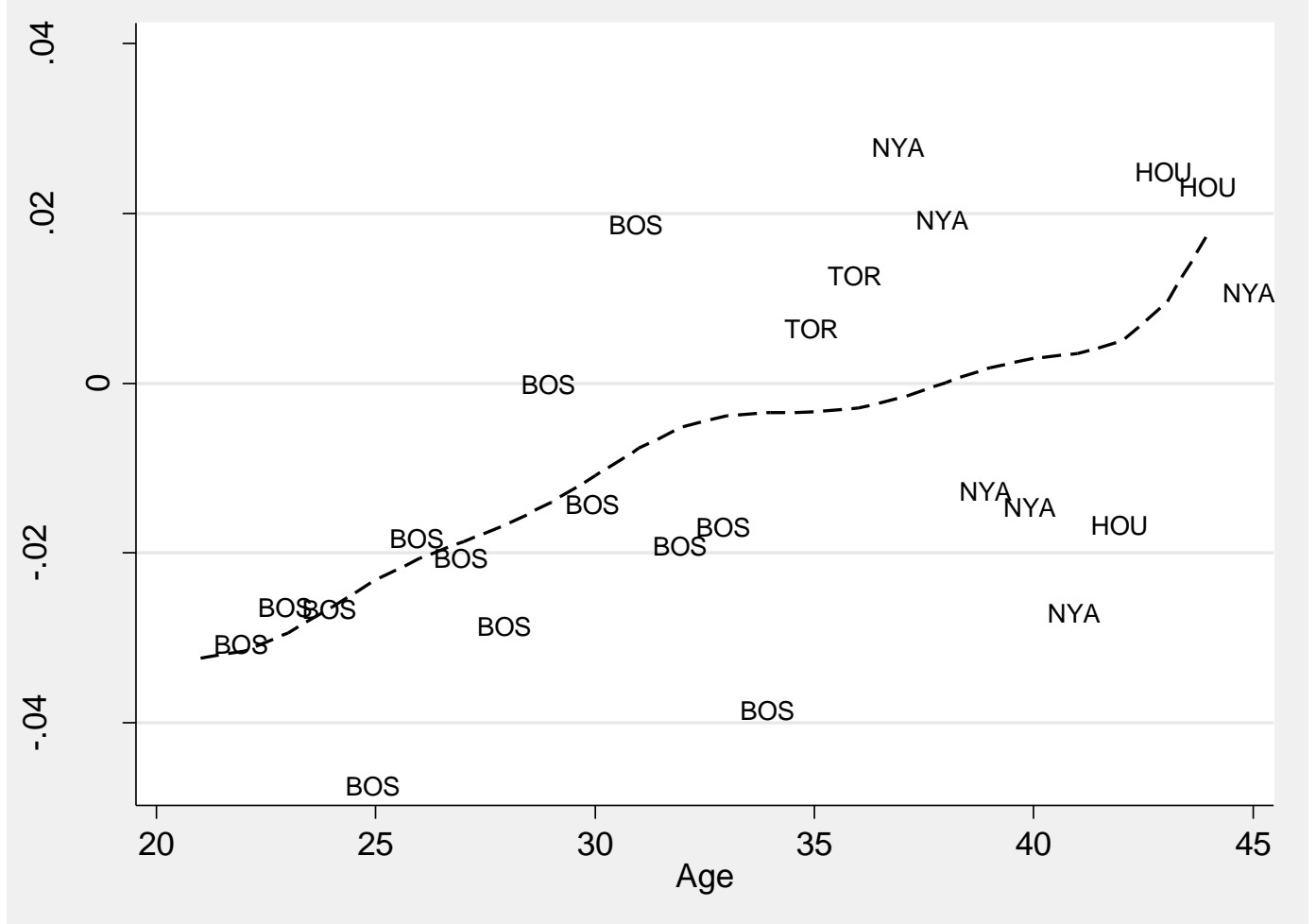

During Clemens's final two seasons in Boston, the Red Sox were ranked $12^{\text {th }}$ and $14^{\text {th }}$ (last) in the American League in defense. Moving to the Toronto Blue Jays in 1997, Clemens experienced an upgrade in the quality of fielders behind him - a trend would continue for his next few years in New York. The Yankees' defense then slowly waned, and even in his first year in Houston he did not have good fielders behind him. In his final two years in Houston, the Astros had the first and second best defenses in the league, where Clemens produced the best and fourth-best ERAs of his career. In his final year, the Yankees had an above-average defense, which was ranked fifth in the league.

The contribution of fielding to Roger Clemens's success has not been discussed in previous analyses; this is an important omission because fielding defense is a significant contributor to overall measures of performance, such as ERA and WHIP. The data reveal that poor fielding early in Clemens's career likely understated the quality of his individual performance, and good fielding late in his career likely boosted his apparent performance above his actual ability.

ii. Pitching Load

The amount that Clemens pitched may have had some influence on his performance and reveal information about the use of performance-enhancing drugs to prolong his career. The expectation is that pitching load will increase and decrease to produce an inverted-J shape, and 
Figure 7 shows, for the most part, Clemens appears to fit this pattern. In terms of innings pitched, Clemens career began with a protected rookie campaign with a limited number of innings per start. His second season he would spend 73 days on the disabled list with an injury, which likely lessened his pitching load over what it might have been. After this point, Clemens's innings pitched ranged between seven and eight innings per start, until his mid-30s. His lowinning averages in 1993 and 1995 were also years in which he spent time on the disabled list with injuries. As Clemens reached his late-30s, his pitching load declined to where he was pitching about six innings per start by the time his career concluded at age 44 .

Figure 7. Roger Clemens's Innings per Game by Age

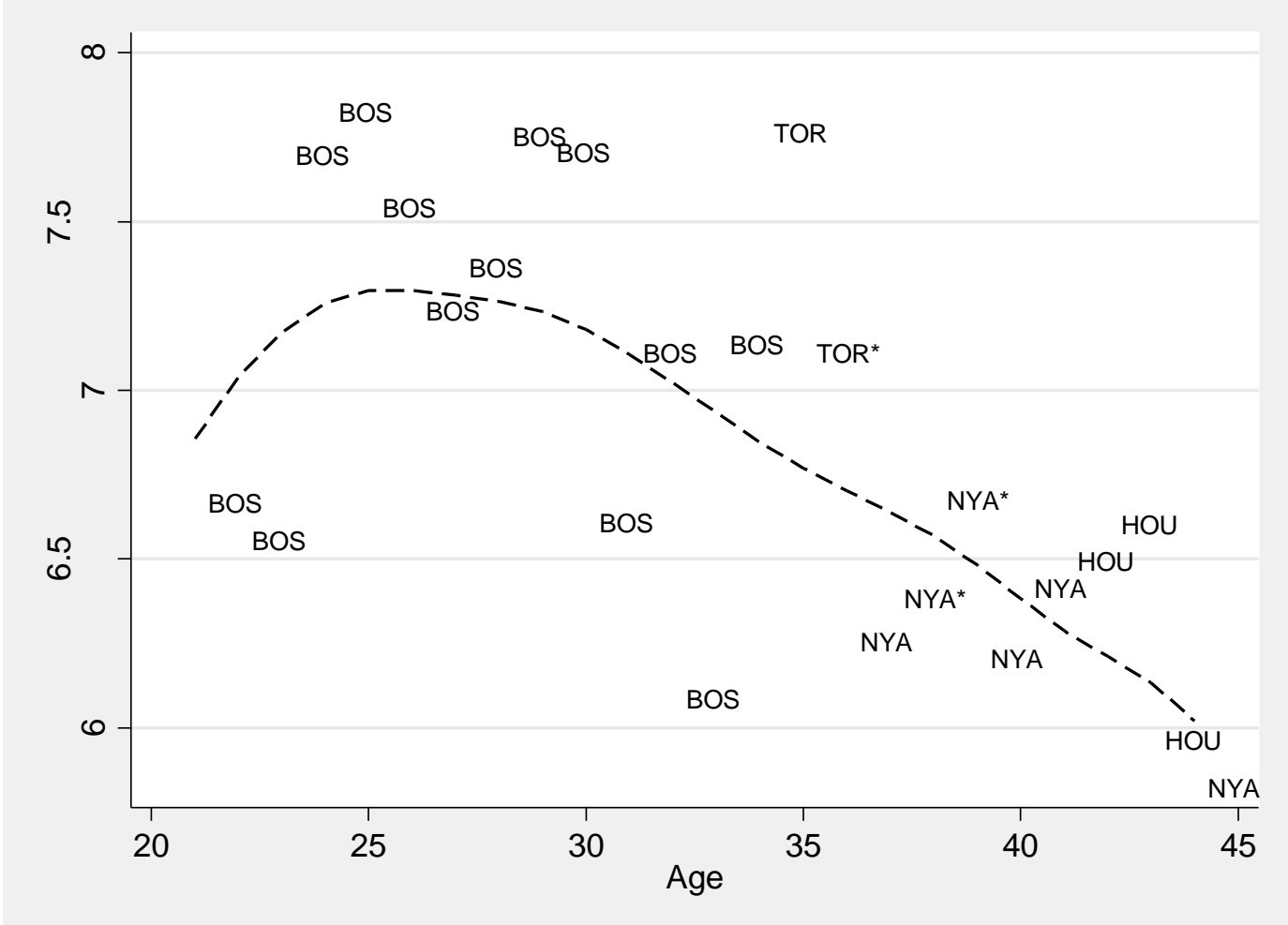

Another measure of his pitching load is how many pitches he threw per game. Figure 8 shows his pitch counts per game, which were not recorded during his entire career, show a steady decline in use per start. The decline in pitching load may have also allowed Clemens to excel during the latter portion of his career. By pitching less, he could pitch harder and have better results for a shorter stint, before turning the game over to relievers. Through age 35 Clemens pitched 114 complete games, but he threw only four complete games from age-36 and older while still remaining an elite pitcher. 
Figure 8. Roger Clemens Pitches per Game Started by Age

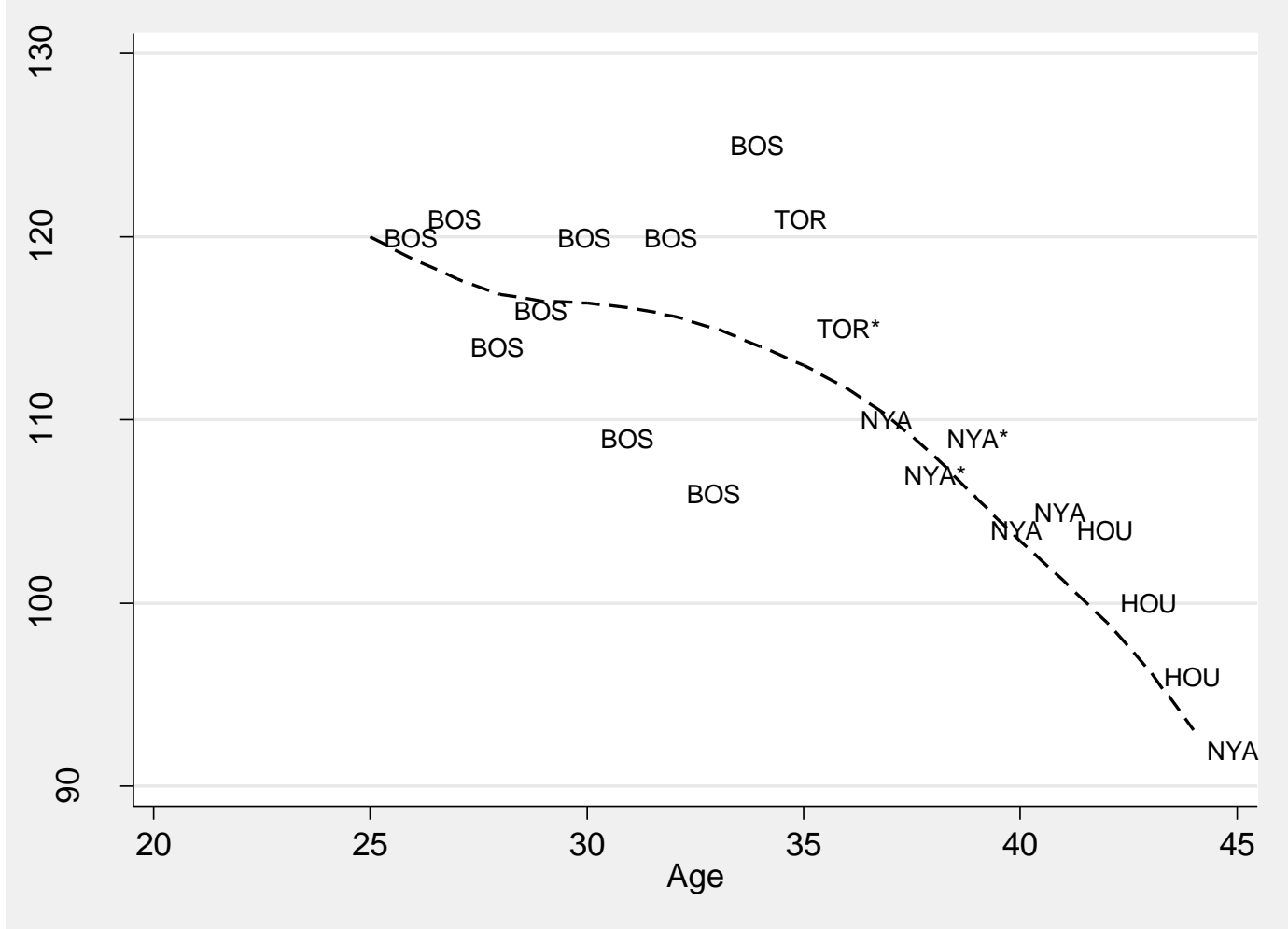

iii. The Houston Effect

Clemens late-career ERA improvement trend is heavily weighted by his performances with the Houston Astros, where he played from 2004 through 2006 (ages 41 through 43). Clemens's Houston years were some of the best of his career. Figure 9 includes Clemens's ERA career trend from Figure 2 along with a trend line that estimates his performance trend excluding his years in Houston.

In 2007, when Clemens returned to pitch for the New York Yankees in a partial-season role, similar to his 2006 stint in Houston, his performance resembled what would be expected from his pre-Houston performance, four years later. If he had retired as he originally planned in after 2003 - which would mean that his career would still encapsulate all the alleged instances of performance-enhancing drug use_- his ERA career performance would look much different than it does and resemble the standard inverted-U shape. The Houston-excluded trend maps a pattern of improvement and decline over his career that fits the standard expectation. Though simply dropping observations to fit an expected pattern is not appropriate, it raises the possibility that there was something unique about his Houston experience that could improve his performance. In this case, Clemens's time in Houston was somewhat different than what most pitchers experience in the last years of their career. 
Figure 9. Roger Clemens's Career ERA by Age with Houston-Excluded Trend

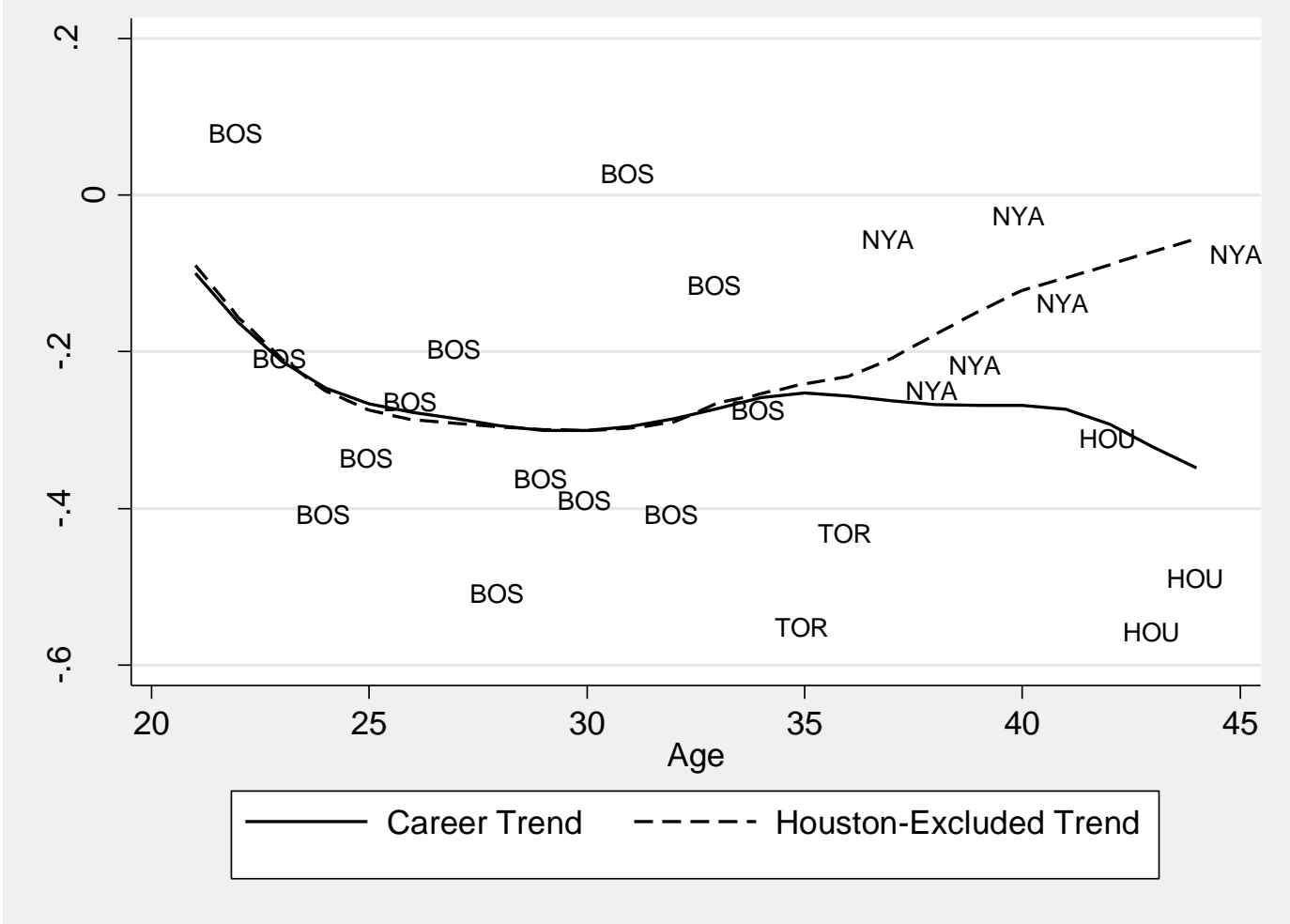

While pitching for the New York Yankees in 2003, Clemens announced that he planned to retire at the end of the season. However, after much wooing by the Astros, Clemens agreed to return to baseball in 2004 for his hometown Astros where he would be allowed to spend more time than usual with his family. Clemens agreed to pitch for a substantial salary discount of $\$ 5$ million-half of what he earned for the Yankees during the previous season. As an incentive to return to the field, the Astros granted Clemens the privilege of spending time away from the team during the season, which meant not traveling to away games when he was not scheduled to pitch, as well as scheduling him to pitch more at home than on the road. ${ }^{8}$

In 2004, Clemens pitched 20 games in Houston and only 13 on the road. In 2005, Clemens returned to Houston for a non-discounted salary of $\$ 18$ million-he was the second-highest paid player in the National League, behind Barry Bonds and tied with teammate Jeff Bagwelland pitched 17 games in Houston and 15 games on the road. In 2006, Clemens did not join the team until June 22 and pitched eleven games at home and eight on the road. During his total

\footnotetext{
8 The informal terms of the deal as reported by ESPN: "Clemens also has an informal understanding that permits him to attend his sons' games during the season when he's not scheduled to pitch. 'Because of who he is, there are a few exceptions we are allowing him to make with our rules,' [Astros general manager Gerry] Hunsicker said. 'His family is a big part of this, so we worked it out. This is a once-in-a-lifetime opportunity. He is one of the greatest to play the game.' The Astros said they will try to pitch Clemens mostly at home.” ESPN.com. Rocket has 1-year deal for $\$ 5$ million, January 14, 2004 (http://sports.espn.go.com/mlb/news/story?id=1706367)
} 
time in Houston, Clemens pitched 57 percent of his games at Houston (48 games at home and 36 games on the road).

In Houston, Clemens's performances in strikeout and walk rates were not noticeably different from his expected career trajectory. In 2004, his strikeout rate was slightly above but similar to his 2003 strikeout rate, and declined in 2005 and 2006. His walk rate fluctuated around his career walk rate trend. Where Clemens did excel was in home run prevention, allowing home runs at half the league-average rate. Figure 10 maps his career trend and Houston-excluded trend which shows his performance in Houston had a divergent impact on his career home run prevention trend.

Figure 10. Roger Clemens's Home Runs Allowed by Age with Houston-Excluded Trend

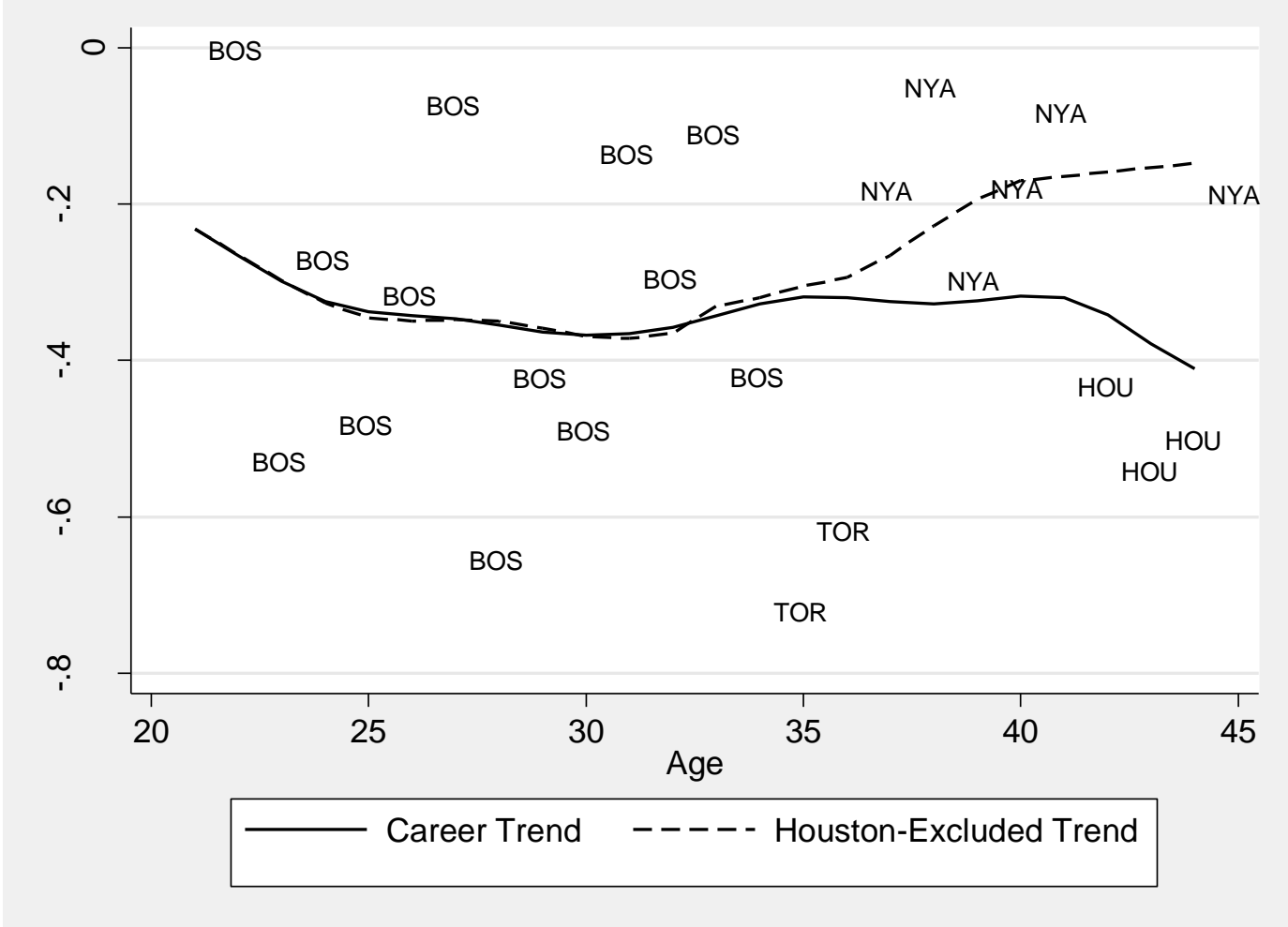

One explanation for a reduced home run rate, especially considering that he pitched more in Houston relative to other parks, is that his home park was individually well-suited for preventing home runs. Clemens did give up fewer home runs at home than he did on the road, but if he allowed home runs at home at the same rate he did on the road, it would produce approximately four more runs-far too small a change to explain his excellence in preventing home runs as an Astro. Preventing home runs is a valuable way to prevent runs; however, preventing home runs is also a much more volatile performance area than strikeouts or walks — a cluster of few good home run years is possible through random fluctuations. 
Table 5 reports the differences in home and away performances in Houston in four areas, in order to assess the impact of the home stadium configuration (or other benefits of playing at home) on several performance metrics. Clemens did perform better at home in all areas, but this is not surprising given that home field advantage is well-documented in sports. However, the revised totals provided in the table recalculate what his performance would have been if he had performed at home the same as he did on the road. ${ }^{9}$ Even when adopting the extreme assumption of equal home-road performance, Clemens's revised Houston ERA would have been 2.64 instead of 2.48—still excellent, and well below his career ERA of 3.12.

Table 5. Roger Clemens’s Houston Performance, Home versus Away (2004-2007)

\begin{tabular}{|c|c|c|c|c|c|c|c|}
\hline \multirow[b]{3}{*}{ Hits } & \multirow{2}{*}{$\begin{array}{c}\text { Home } \\
\text { (per Plate }\end{array}$} & \multirow{2}{*}{$\begin{array}{c}\text { Away } \\
\text { ppearance) }\end{array}$} & \multirow{2}{*}{$\begin{array}{c}\% \text { Improvement } \\
\text { at Home }\end{array}$} & \multicolumn{2}{|c|}{ Home Totals } & \multicolumn{2}{|c|}{ Saved } \\
\hline & & & & Actual & Revised & Outcomes & Runs \\
\hline & 0.18755 & 0.19037 & $1.50 \%$ & 235 & 239 & 4 & 2 \\
\hline Strikeouts & 0.23783 & 0.22648 & $-4.77 \%$ & 298 & 284 & 14 & 4 \\
\hline Walks & 0.07263 & 0.08643 & $19.01 \%$ & 91 & 108 & 17 & 6 \\
\hline Home Runs & 0.01437 & 0.01641 & $14.24 \%$ & 18 & 21 & 3 & 4 \\
\hline \multirow[t]{3}{*}{ Total Runs Saved } & & & & & & & 15 \\
\hline & & & & \multicolumn{2}{|c|}{ Totals } & & \\
\hline & & & & Actual & Revised & & \\
\hline Earned Runs & & & & 144 & 159 & & \\
\hline ERA & & & & 2.48 & 2.64 & & \\
\hline
\end{tabular}

The peculiarities of playing at home do not appear to be sufficient to explain Clemens's excellent performances in Houston. Any benefits he experienced from his time in Houston (e.g., his flexible travel schedule) affected his overall performance, not just his home performance. The permission to spend days on which he did not pitch away from the team may have provided advantages such as sparing him from the rigors of travel and making him happier by allowing him to spend more time with his family. No matter the reason, it is important to acknowledge the important role of Clemens's tenure in Houston impacting the trend of his late-career success; yet, this period of excellence occurred three-to-five years after his last alleged performance-enhancing drug administration.

\section{Comparing Clemens to Similar Pitchers}

The two previous studies that have examined Roger Clemens's performance statistics in order in search of evidence that might indicate performance-enhancing drug use created cohorts of pitchers to compare Clemens. Bradlow et al. (2008) uses a group of 32 pitchers who pitched at least 15 seasons as a starter (with ten or more games per year), pitched 3,000 or more innings in the included seasons, and whose careers were bounded between 1969 and 2007. The motivation

\footnotetext{
${ }^{9}$ Run value estimates derived from Gillette and Palmer (2005, p. 1711) Batting Runs formula which is based on Thorn and Palmer (1984).
} 
for using the selected criteria was because these pitchers had long careers similar to Clemens. ${ }^{10}$ The authors estimate a quadratic fit of each pitcher's career in the sample for ERA, WHIP, walk (BB) rate, strikeout rate, and batting average allowed in order to identify 'atypical' careersatypical is defined as a quadratic coefficient estimate that has the opposite of the expected sign. For ERA, Clemens is one of six pitchers in the sample (19 percent) with an atypical career. For WHIP, Clemens is one of seven pitchers (22 percent) with an atypical quadratic term. For walks, Clemens is one of 10 pitchers (31 percent) in the sample with an atypical career path, but the authors also note that the slope of late-career improvement was "particularly noticeable in the later years, even among this set of $10 . " 11$ In terms of strikeout rates and batting average allowed, the estimates indicate that Clemens's career trajectory was typical. The authors conclude "that Clemens' pitching career was atypical for long-term pitchers in terms of WHIP, $\mathrm{BB}$ rate, and ERA. In particular, Clemens shows a mid-career decline followed by an end-ofcareer improvement that is rarely seen."

Albert (2009) generated a cohort of 34 pitchers who faced at least 5,000 hitters, debuted in the major leagues between 1948 and 2007, and were estimated to have peak WHIP abilities (transformed to account for changes in the playing environment) of greater than 1.5 standard deviations above average at their estimated peak age. ${ }^{12}$ The analysis produced the conclusion that Clemens is among a group of seven pitchers (20 percent of the sample) "who displayed an unusual pattern for mature ages." The group also included Dennis Eckersley, Randy Johnson, Gaylord Perry, Nolan Ryan, Don Sutton, and Hoyt Wilhelm. It is interesting that measured as a percentage, Clemens membership in the unusual performance group is similar to what Bradlow et al. (2008) identifies; however, the interpretation in Albert (2009) is different, "Clemens displayed unusually strong pitching ability toward the end of his career, but there were six other pitchers in our study who also displayed similar residual trajectories and none of these pitchers has been accused of using steroids."

The Albert sample was generated to compare players who had similar peaks and does not rely on a restriction of a quadratic function for measuring career paths. The Bradlow et al. (2008) cohort includes a broader set of performance metrics and restricts the analysis to performance of long careers as a starter. I developed an alternate cohort in order to analyze a broader set of performance areas and choose a group of similarly-performing starting pitchers during their peak years whose entire careers (from debut to retirement) occurred between 1920 and 2009. This

\footnotetext{
${ }^{10}$ Attempts to replicate this sample from the stated criteria were unsuccessful; therefore, I used all the pitchers included on their cohort list reported in an earlier unpublished draft of the paper. No matter what the exact selection criteria were, this group of pitchers meet the intent of creating a comparison durable starting pitchers who played in the modern era.

${ }^{11}$ I disagree with this last point, as visual inspection of the reported graph indicates that about half the sample has near equal or steeper slopes than Clemens.

12 WHIP is traditionally calculated as [Walks + Hits]/Innings Pitched, but Albert (2009 uses "a slight abuse of notation" to produce "WHIP" using [Walks + Hits]/ Batters Faced. This is an acceptable transformation, especially after it is normalized to control for different performance environments over time. Thus, in this paper, I continue to use WHIP to define the Albert (2009) metric as it remains comparable to the traditional WHIP calculation used in Bradlow et al. (2008).
} 
"Peak Age" cohort includes pitchers who had an ERA that was 20-percent better than league average from ages 28 to 32 and who started at least ten games in a season in at least four of the five years in this age range. Only seasons in which a pitcher started at least ten games were included in the sample to avoid bias created by a starter being converted primarily to a reliever. The criteria select a sample of pitchers who were nearly as good as Clemens during their typical peak-age range-Clemens's ERA was 25-percent better than average during this age range. The inclusion criteria resulted in a sample of 30 pitchers.

The pitchers in all three cohorts used in this paper and their career spans are listed in Table A.1 in the Appendix. In total, the cohorts include a total of 67 different pitchers between them, including Clemens. The samples overlap, but each cohort includes more unique than overlapping observations, which provides three samples of similar but unique comparison groups for Clemens. Table 6 reports the overlap of pitchers in each sample.

Table 6. Cohort Overlap Matrix

\begin{tabular}{|l|c|c|c|}
\hline & Albert & Bradlow et al & Peak Age \\
\hline Albert & 34 & 14 & 13 \\
\hline Bradlow et al. & 14 & 32 & 11 \\
\hline Peak Age & 13 & 11 & 30 \\
\hline
\end{tabular}

Figures 11-14 report the Lowess fit career trends of the different cohorts (excluding Clemens) and Roger Clemens, all bounded between Clemens's career ages from 21 to 44. Figures A.1-A.4 in the Appendix provide individual career trend estimates for all pitchers in the Peak Age cohort.

Figure 11 reports the changes in performance of ERA for all three cohorts and Clemens. In terms of overall performance, Clemens's ERA career trend shows an improvement and decline that is consist with other similar pitchers until he reaches his mid-30s, when his performance leveled off and then improved into his 40s. Both the Peak Age and Bradlow et al. cohort pitchers experienced a continued steady rising ERAs consistent with the deterioration of age, but the Albert cohort is different. The Albert cohort performance nearly matches the Bradlow et al. cohort performance up until the late-30s, when the Albert cohort shows a shallower decline in performance and slight improvement into the 40s. Though the improvement is not as extreme as Clemens, it does show that a group of similar pitchers experienced a resurgence in performance late in their careers like Clemens.

Figure 12 maps the strikeout trends of the cohorts, and Clemens's performance does not appear to be to anything unique about his performance in this area. This is a conclusion reached by Bradlow et al. (2008) as well in its analysis of quadratic career trajectories. Thus, in the performance area that is the most likely channel for an ergogenic aid to improve the performance of a pitcher, Clemens's performance was similar to other pitchers. 
Figure 11. Career ERA Performance by Cohort

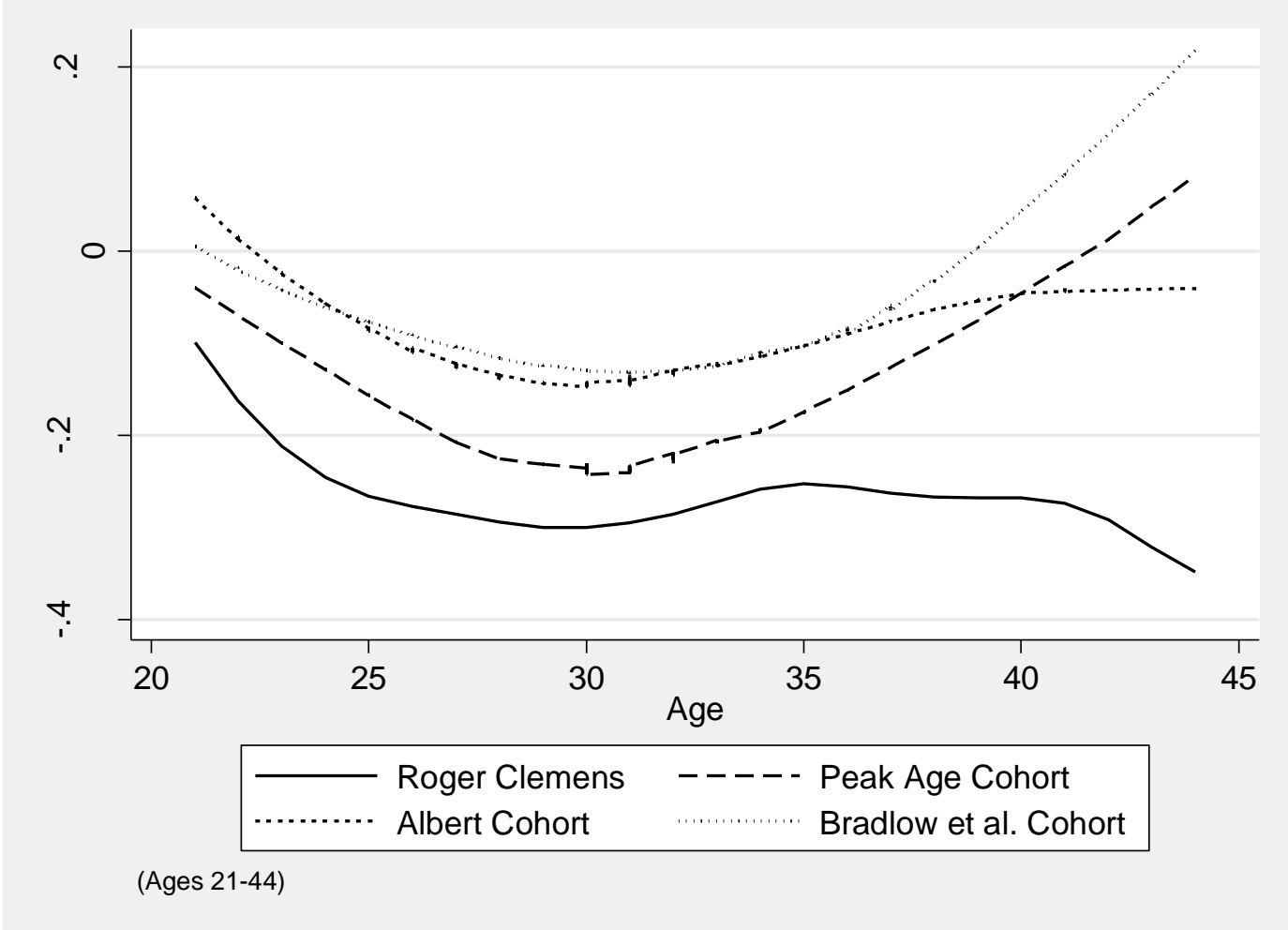

Figure 12. Career Strikeout Performance by Cohort

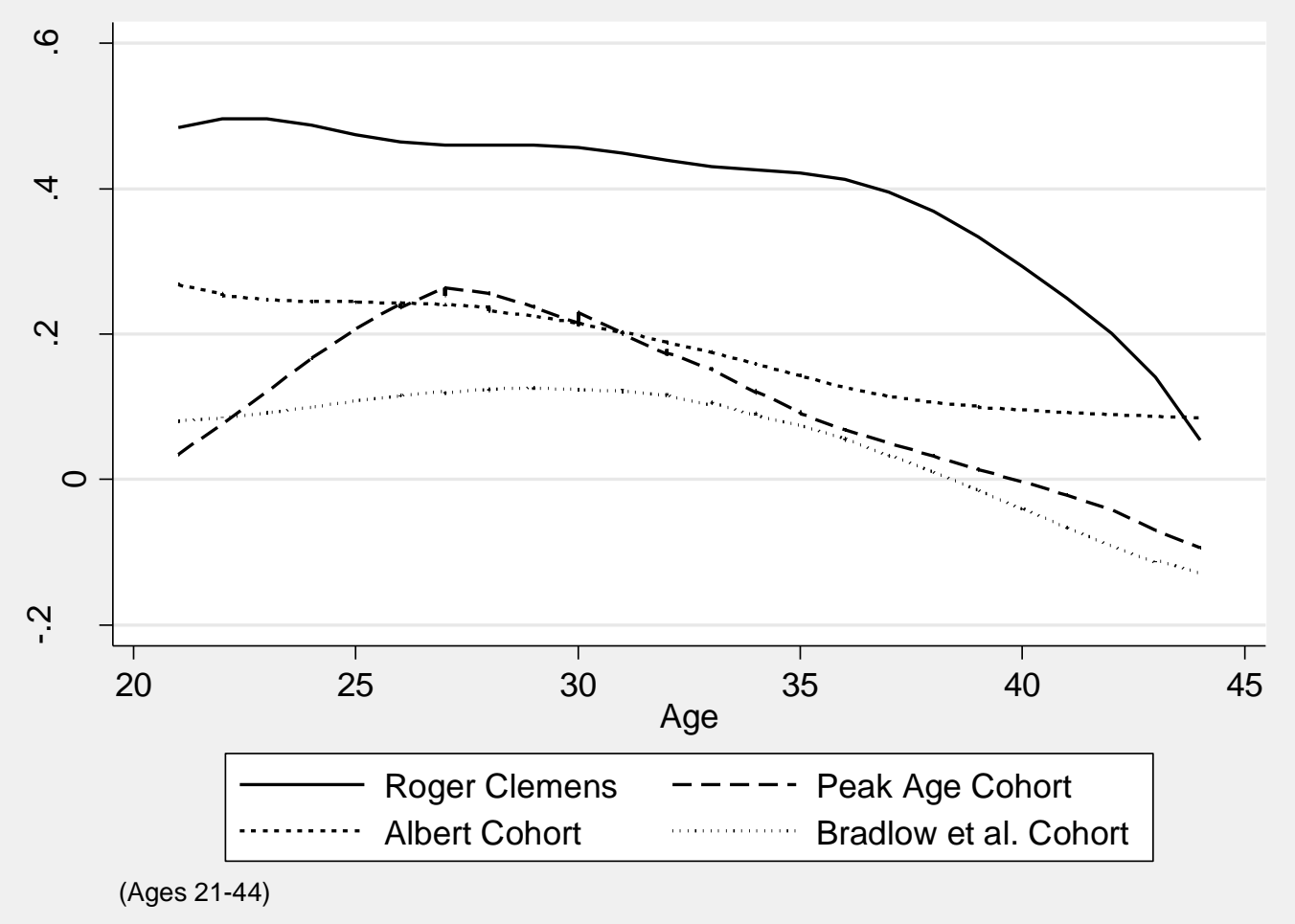


Figure 13 shows the most curious aspect of Clemens's career, his inverse pattern of walking batters as he aged. This difference was noted explicitly by Bradlow et al. (2008), and we can infer the same from Albert (2009) in its analysis of WHIP, which has the walk rate of as one of its two components. The Bradlow et al. cohort has the standard pattern of improvement and deterioration of walk prevention ability that peaks in the mid-30s before steadily rising. However, both the Albert and Peak Age cohorts show continued declining walk rate at a diminishing rate. While the rate of improvement is not as pronounced as Clemens's it does provide evidence, contrary to Bradlow et al. (2008), of simliar pitchers improving well into their early-40s. What is less odd about Clemens's career walking batters is not his late-career improvement, but that his extreme decline in his mid-20s to mid-30s. The individual career trends for walks, reported in Figure A.3, reveals that approximately half of the pitchers in the sample experienced continuing or resurgent late-career improvements in walk prevention. This provides further evidence that the large contribution which improved walk prevention played in aiding Clemens's overall performance was not uncommon among similar pitchers. Furthermore, walks are the area least likely to be improved-alone, without the corresponding improvement in strikeouts-by performance-enhancing drugs.

Figure 13. Career Walk Performance by Cohort

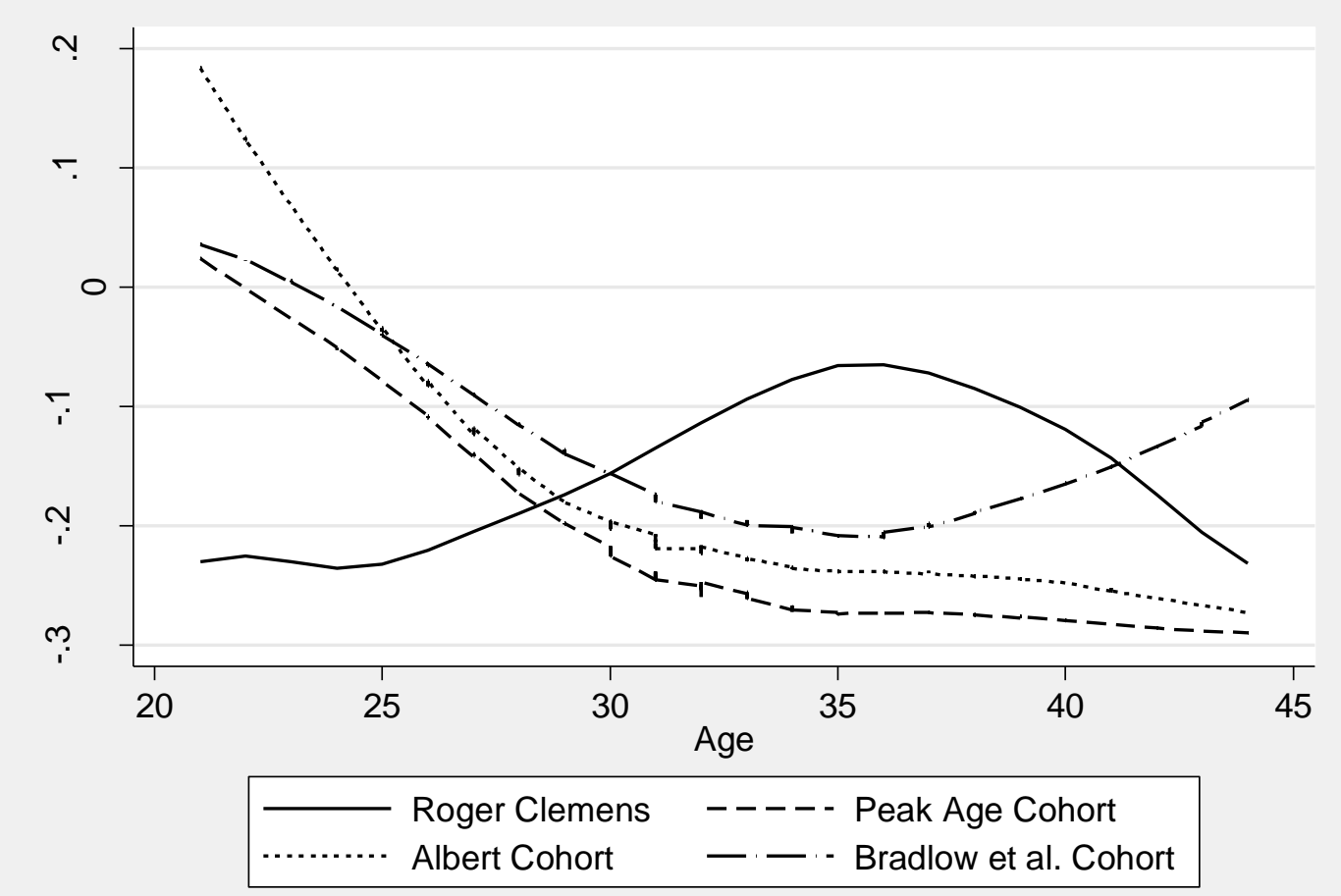

(Ages 21-44)

As noted above, Clemens's home run prevention does not show a strong pattern over his career, but the estimated trend is a period of standard improvement and decline, followed by an atypical leveling off and improvement from his mid-30s into his 40s. Figure 14 shows that the Bradlow 
et al. and Peak Age cohorts allowed more home runs as they aged, as expected. However, the Albert cohort has a shape that is closer to flat than an actual change in performance, but the shape it does have is a counterintuitive shape of shallow decline and shallow improvement.

Figure 14. Career ERA Performance by Cohort

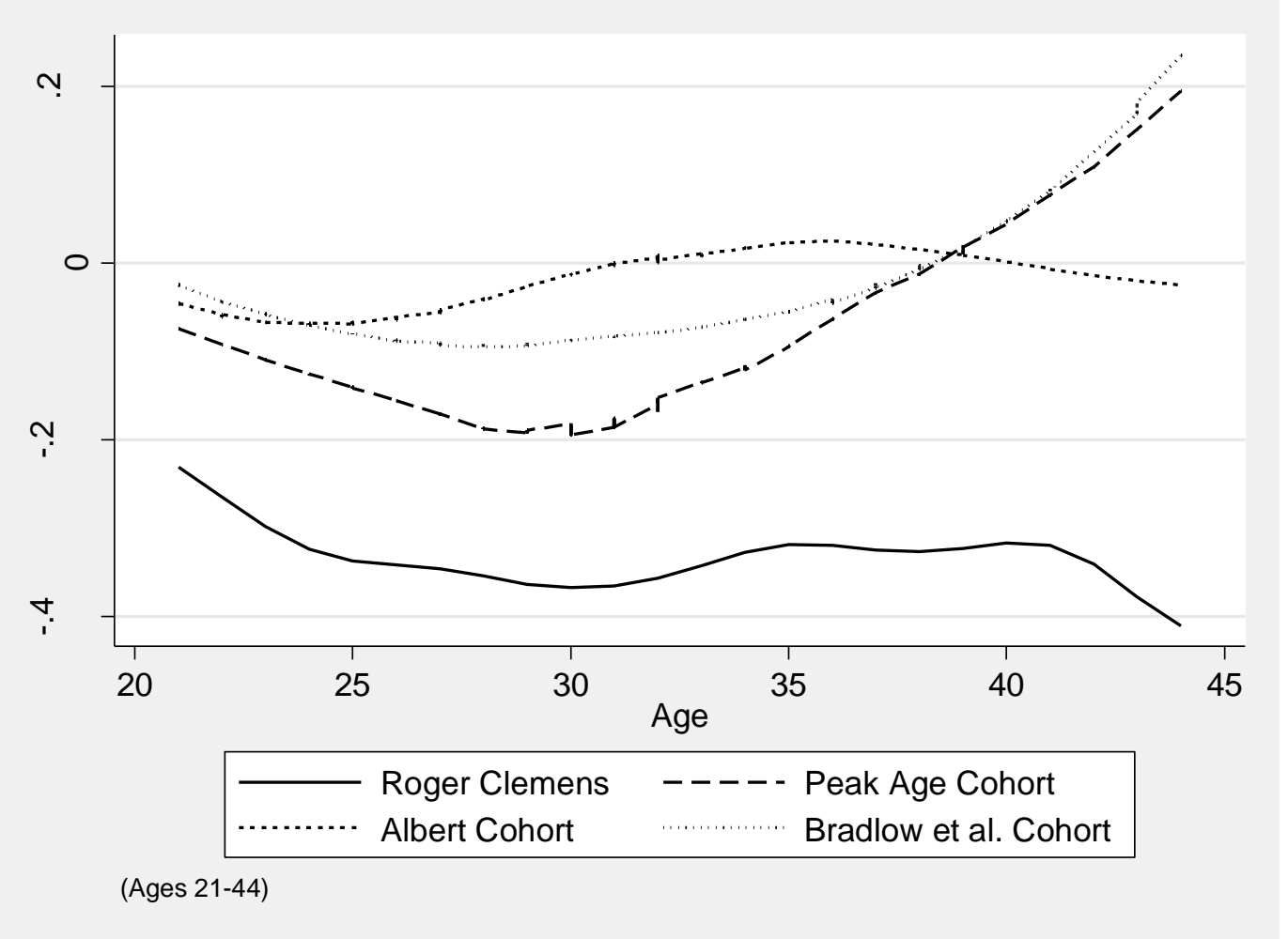

The length of Roger Clemens's career is also considered evidence of his using an ergogenic aid to prolong his career; however, long careers are quite common among excellent pitchers. Table 7 lists the ten pitchers who are most similar to Roger Clemens in terms of their career performances as identified by Baseball-Reference.com. Seven of the pitchers pitched into their 40s, and the three who did not (Nichols, Clarkson, and Keefe) pitched in the 19th century. And this list does not include Clemens's idol, fellow Texan Nolan Ryan who pitched until he was 46 and is also a Hall-of-Fame member. Good pitchers tend to pitch for a long time, just like Clemens did. There is nothing abnormal about Roger Clemens pitching so well for so long, because numerous excellent pitchers have done so as well. 40 percent of Hall-of-Fame pitchers pitched into their 40s, and 19 percent pitched at age 44 and beyond, including Randy Johnson, Nolan Ryan, Warren Spahn, and Cy Young.

A comparison of Roger Clemens to similar baseball pitchers indicates that while his career was different in some respects, other pitchers demonstrated similar tendencies, which indicates Clemens's career was not as atypical as it might seem. 
Table 7. End-of-Career Ages for Most-Similar Pitchers to Roger Clemens

\begin{tabular}{|l|l|c|}
\hline Rank & Pitcher & End of Career Age \\
\hline 1 & Randy Johnson & 46 \\
\hline 2 & Greg Maddux & 42 \\
\hline 3 & Tom Seaver & 41 \\
\hline 4 & Steve Carlton & 43 \\
\hline 5 & Don Sutton & 43 \\
\hline 6 & Warren Spahn & 44 \\
\hline 7 & Tom Glavine & 42 \\
\hline 8 & Kid Nichols & 36 \\
\hline 9 & John Clarkson & 33 \\
\hline 10 & Tim Keefe & 36 \\
\hline
\end{tabular}

\section{Twilight Resurgence}

Another common argument for Roger Clemens having used performance-enhancing drugs is that his career experienced a sharp resurgence after he joined the Toronto Blue Jays, at a time when he was referred to as entering the "twilight" of his career by his previous General Manager. His excellent years in Toronto also nearly coincide with his alleged first use of performance-enhancing drugs; however, the break-point in performance does not exactly match, as his first season in Toronto occurred one year prior to his first alleged use of performanceenhancing drugs. Sports commentator Dan Patrick put forth an example of this argument, “Clemens wouldn't have been a Hall-of-Famer without using. People are so wrong on that. He was done in Boston. He was washed up in Boston. And he found a needle in Toronto, and became a Hall-of-Fame pitcher."13

To many baseball fans, Clemens appeared to be in decline in Boston. He would pitch two excellent seasons for the Toronto Blue Jays in 1997 and 1998, winning the AL Cy Young Award and the "triple crown" in both years. He would pitch for the Yankees from 1999 to 2003 and 2007—winning the AL Cy Young in 2001 — and for the Astros from 2004 to 2006, winning the NL Cy Young in 2004.

During his last four seasons in Boston, Clemens would not make the All-Star team or receive any $\mathrm{Cy}$ Young votes. In comparison to Clemens's early career-when Clemens had won three Cy Young Awards, one Most Valuable Player Award, and been selected to six All-Star teamsthis was disappointing and unexpected to many Red Sox fans. His departure from the Red Sox for a lucrative free-agent contract further exacerbated negative feelings about Clemens. However, his final years in Boston were also beset with injuries, labor strife, low run support, and some bad Boston teams that prevented many observers from noticing that Clemens was pitching well, or had good reasons to be pitching below his established level for this period of

${ }^{13}$ Dan Patrick, 1/6/2016, 10:19am 
time. Though this epoch of Clemens career was not his best, his performance was not so far removed from his past excellence as some people might believe.

Table 9 highlights some of Clemens's woes during his last four years in Boston. He never won more than eleven games, which was far less that the 19 Wins he averaged in the preceding seven seasons, but his run support — an important determinant of Wins, over which he had no control-was below league average in three of the four seasons. The Red Sox also made the playoffs only once during this span. In 1993 and 1995, Clemens had to be placed on the disabled list, which cost him time on the field and hampered his performance.

Table 9. Rogers Clemens’s Poor Performances in Boston (1993-1996)

\begin{tabular}{|cccccccc|}
\hline Season & W-L & Run Support & AL Runs per Game & Team W-L & Team Finish & Games & DL Days \\
\hline 1993 & $11-14$ & 3.3 & 5.4 & $80-82$ & 5 th & 29 & 27 \\
1994 & $9-7$ & 3.9 & 5.1 & $54-61$ & 4 th & 24 & 0 \\
1995 & $10-5$ & 5.7 & 5.2 & $86-58$ & 1 st & 23 & 38 \\
1996 & $10-13$ & 4.3 & 4.7 & $85-77$ & 3 rd & 34 & 0 \\
\hline
\end{tabular}

During seasons in which he was injured, Clemens's performance suffered, which is not surprising. In his healthy 1994 and 1996 seasons, Clemens continued to be one of the league's most dominant pitchers. Table 10 reports Clemens's performance in areas where he performed well. In the strike-shortened 1994 season, he was second in ERA, strikeouts, and strikeout rate. In 1996, he led the league in strikeouts and strikeout rate and had the league's seventh-best ERA. Clemens averaged 125 pitches per start — the highest average of his career-and he would strike out 20 batters in a single game in September 1996. Even during his injured 1993 and 1995 campaigns he was fourth in the league in strikeout rate. The next-to-last column of the table shows the hypothetical strikeouts that Clemens would have had if he had pitched the same number of innings as he did in 1996, when he was fifth in the league in innings pitched. This extends the strike-shortened 1994 and 1995 seasons and puts back time lost to injuries in 1993 and 1995. In every year, Clemens was on pace to have more than 200 strikeouts, and was among the top-five pitchers in strikeout rate. These are hardly mediocre performances, and indicate that Clemens was still one of the league's elite pitchers.

Table 10. Rogers Clemens's Good Performances in Boston (1993-1996)

\begin{tabular}{|ccccccccccc|}
\hline \multirow{2}{*}{ Season } & \multicolumn{2}{c}{ IP } & \multicolumn{2}{c}{ ERA } & \multicolumn{2}{c}{ Strikeouts } & \multicolumn{2}{c}{ Strikeouts per 9 IP } & \multicolumn{2}{c|}{ Strikeouts } \\
Pitches/ \\
& Total & Rank & Average & Rank & Total & Rank & Average & Rank & (per 242.67 IP) & Game \\
\hline 1993 & 191.67 & -- & 4.46 & -- & 160 & -- & 7.51 & 4 & 203 & 109 \\
1994 & 170.67 & 9 & 2.85 & 2 & 168 & 2 & 8.86 & 2 & 239 & 120 \\
1995 & 140 & -- & 4.18 & -- & 132 & -- & 8.49 & $4 *$ & 229 & 106 \\
1996 & 242.67 & 5 & 3.63 & 7 & 257 & 1 & 9.53 & 1 & 257 & 125 \\
\hline
\end{tabular}

* Unofficial, lacked minimum qualifying innings pitched 
Clemens may have seemed to be going through a rough patch in his career, however, he remained one the league's best pitchers, and most of his troubles were beyond his control. And his dominant 1996 campaign, rather than ushering in his “twilight,' signaled a Clemens who was healthy and ready to compete for more Cy Young Awards. The Toronto Blue Jays apparently felt so when they made him the game's highest paid pitcher in 1997 and 1998. If Clemens's skills were in obvious decline, it would be odd for a team to make him such a lucrative offer.

As evidence of Clemens's performance-enhancing drug use, Bradlow et al. (2008) also highlights Clemens's performance during his last four years with the Boston Red Sox ("he lost his relative luster") and subsequent resurgence ("Clemens recovered and climbed to new heights at the comparatively old age of 35") as unusual when compared to four "star-level contemporaries" (Greg Maddux, Randy Johnson, Curt Schilling, and Nolan Ryan). However, the trends differ because they are derived from different estimation methods. Clemens's performance is estimated using spline fitting, while the trend maps for the other pitchers are estimated as quadratic functions, which not only uses each pitcher's entire career data, but it imposes a predetermined functional form of the entire career of the pitcher. Clemens's up-and-down performance as presented in Bradlow et al. (2008) looks odd compared to the other pitchers not because his career is odd, but because the trend maps are estimated by completely different estimation techniques: one that creates a naturally wavy trend for Clemens and one that creates a smooth behaved trend for the comparison pitchers. The analysis in Section 6 provides better context for changes in Clemens's performance as compared to other pitchers.

Thus, the statistical case that Clemens experienced a late-career bump in his performance during the so-called "twilight' period of his career is quite weak. While Clemens did pitch well late in his career, and that good pitching is apparent in his latter-career averages, most of his extraordinary late-career success occurred many years later in Houston, after his last alleged use of performance-enhancing drugs. His improvements in Toronto were consistent with the way he was pitching in Boston, and even if the Toronto performance is viewed as a significant improvement, its manifestation occurred one-year prior to his alleged first administration of performance-enhancing drugs.

\section{Discussion and Conclusion}

A close examination of Roger Clemens's career performance reveals what was obvious to casual baseball fans: Roger Clemens had a long career of excellence that make him one of the best pitchers in the history of the game. The accusations of performance-enhancing drug use provide three reference points of use. However, the main periods of late-career success that Clemens experienced occurred many years after the alleged use occurred in Houston.

As for his sustained career of excellence, where Clemens's career is most odd is in walking batters, which is unlikely to result from using performance-enhancing drugs designed to increase strength and power without a corresponding increase in strikeouts. However, Clemens's 
strikeout rate declined throughout his career, and is perhaps the most normal aspect of his age progression. About the time of his improvement in walking batters, Clemens changed his approach to pitching, which was well-documented by the media in order to compensate for his diminishing physical skill. Clemens also benefitted from several positive circumstances that fostered a late-career resurgence from an already-successful baseball pitcher: he was allowed to pitch for his hometown team, with special permission to travel less and spend time with his family; he moved from mostly bad-fielding teams to teams with good fielders; and he reduced his workload which may have allowed him to trade quantity for quality in pitching.

It is impossible to prove that Clemens did not use performance-enhancing drugs to lengthen and improve his career. But this analysis does not find much, if any, indicator of performanceenhancing drug use within his performance statistics. The data reveal that Clemens performance was excellent, event among baseball's historically-elite pitchers; however, his sustained excellence is not unique among excellent pitchers who have not been accused of using performanceenhancing drugs, nor did many of them live in an era when performance-enhancing drugs were widely used or even available. Clemens's career progressed and how he improved through lowering his walk-rate is consistent with other notable pitchers' careers. There are no obvious deviations in his statistical record that indicate the use of performance-enhancing drugs; and the most notable late-career performances that might be considered rare occurred well after he was alleged to have used performance-enhancing drugs. While no amount of data analysis can exonerate Clemens of taking performance-enhancing drugs, there is very little indication within his performance record that can convict him nor to support existing specific allegations of use.

It could be argued that other instances of Clemens's use have not been discovered, and therefore deviations in performances at alleged specific instances are not so unexpected. However, the FBI's investigation of Clemens included 235 interviews of 179 people at 68 locations with the assistance of 93 officers and four Assistant U.S. Attorneys. Given the stakes and amount of resources devoted to the case, it seems likely that additional evidence of use would have been discovered if it existed. Perhaps evidence of additional use is yet to be discovered, but the presumption of innocence, by even the lowest standards of for declaring guilt, should remain with Clemens. 


\section{References}

Adair, R.K. (1994). The Physics of Baseball, $2^{\text {nd }}$ edition, Revised, Updated, and Enlarged. New York: HarperCollins.

Albert, J. (2009). Is Roger Clemens’ WHIP trajectory unusual? Chance, 22(4):9-20.

Bradbury, J.C. (2007). Does the baseball labor market properly value pitchers? Journal of Sports Economics, 8, 616-632.

Bradbury, J.C. (2009). Peak athletic performance and ageing: evidence from baseball. Journal of Sports Sciences, 27(6): 599-610.

Bradbury, J.C. (2010). Hot Stove Economics: Understanding Baseball's Second Season. New York: Copernicus.

Bradbury, J.C. (2013). Did Jose Canseco Really Improve the Performance of His Teammates by Spreading Steroids? A Critique of Gould and Kaplan. Econ Journal Watch, 10(1): 40-69

Bradlow, E., Jensen, S., Wolfers J., and Wyner, A. (2008). A statistical look at Roger Clemens' career. Chance, 21(3):24-30.

Duggan, M. and Levitt, S.D. (2002). Winning isn't everything: corruption in sumo wrestling. The American Economic Review, 92 (5): 1594-1605.

Gillette, G. and Palmer, P. (2005). The 2005 ESPN Baseball Encyclopedia. New York: Sterling.

Gould, E.D., and Kaplan, T.R. (2011). Learning unethical practices from a co-worker: The peer effect of Jose Canseco. Labour Economics, 18(3): 338-348.

Gould, Eric D., and Kaplan, T.R. (2013). The peer effect of Jose Canseco: A reply to J. C. Bradbury. Econ Journal Watch, 10(1): 70-86.

Hendricks, R., Mann, S., and Larson-Hendricks, B. (2008). An analysis of the career of Roger Clemens. (http://www.rogerclemensreport.com/reports/ClemensReport.pdf)

Mayo, J. (2008). Facing Clemens: Hitter on Confronting Baseball's Most Intimidating Pitcher. Guilford, CT: The Lyons Press.

Mitchell, G.J. (2007). "Report to the Commissioner of Baseball of an Independent Investigation into the Illegal Use of Steroids and Other Performance Enhancing Substances by Players in Major League Baseball.” December 13, 2007. (http://mlb.mlb.com/mlb/news/mitchell/) 
Over, R. and Thomas, P. (1995). Age and skilled psychomotor performance: A comparison of younger and older golfers. International Journal of Aging and Human Development, 41, $1-12$.

Stacy, J.J., Terrell, T.R. and Armsey, T.D. (2004). Ergogenic aids: human growth hormone. Current Sports Medicine Reports, 3(4): 229-333.

Thorn, J. and Palmer, P. (1984). The Hidden Game of Baseball: A Revolutionary Approach to Baseball and Its Statistics. New York: Doubleday.

Tobin, R. G. (2008). On the potential of a chemical Bonds: possible effects of steroids on home run production in Baseball. American Journal of Physics, 76(1): 15-20. 
Table A.1. Pitcher Cohort Groups

\begin{tabular}{|c|c|c|c|c|c|c|c|c|}
\hline \multicolumn{3}{|c|}{ Albert Cohort } & \multicolumn{3}{|c|}{ Bradlow et al. Cohort } & \multicolumn{3}{|c|}{ Peak Age Cohort } \\
\hline Player & $\begin{array}{c}\text { Debut } \\
\text { Year }\end{array}$ & Final Year & Player & Debut Year & Final Year & Player & Debut Year & Final Year \\
\hline Andy Messersmith & 1968 & 1979 & Bert Blyleven & 1970 & 1992 & "Billy Pierce & 1945 & 1964 \\
\hline Bob Gibson & 1959 & 1975 & Bob Welch & 1978 & 1994 & Bob Gibson & 1959 & 1975 \\
\hline Catfish Hunter & 1965 & 1979 & Chuck Finley & 1986 & 2002 & Bob Lemon & 1941 & 1958 \\
\hline Curt Schilling & 1988 & 2007 & Curt Schilling & 1988 & 2007 & Bob Welch & 1978 & 1994 \\
\hline Dennis Eckersley & 1975 & 1998 & David Wells & 1987 & 2007 & Carl Hubbell & 1928 & 1943 \\
\hline Dennis Martinez & 1976 & 1998 & Dennis Martinez & 1976 & 1998 & Curt Schilling & 1988 & 2007 \\
\hline Dick Hall & 1952 & 1971 & Don Sutton & 1966 & 1988 & David Cone & 1986 & 2003 \\
\hline Don Drysdale & 1956 & 1969 & Doyle Alexander & 1971 & 1989 & Dizzy Trout & 1939 & 1957 \\
\hline Don Newcombe & 1949 & 1960 & Fergie Jenkins & 1965 & 1983 & Dutch Leonard & 1933 & 1953 \\
\hline Don Sutton & 1966 & 1988 & Frank Tanana & 1973 & 1993 & Ed Lopat & 1944 & 1955 \\
\hline Dwight Gooden & 1984 & 2000 & Gaylord Perry & 1962 & 1983 & Gaylord Perry & 1962 & 1983 \\
\hline Fergie Jenkins & 1965 & 1983 & Greg Maddux & 1986 & 2008 & Greg Maddux & 1986 & 2008 \\
\hline Fernando Valenzuela & 1980 & 1997 & Jack Morris & 1977 & 1994 & Harry Brecheen & 1940 & 1953 \\
\hline Gaylord Perry & 1962 & 1983 & Jamie Moyer & 1986 & 1985 & Jim Palmer & 1965 & 1984 \\
\hline Greg Maddux & 1986 & 2008 & Jerry Koosman & 1967 & 1990 & John Smoltz & 1988 & 2009 \\
\hline Hoyt Wilhelm & 1952 & 1972 & Jerry Reuss & 1969 & 1984 & Johnny Allen & 1932 & 1944 \\
\hline J.R. Richard & 1971 & 1980 & Jim Palmer & 1965 & 1988 & Juan Marichal & 1960 & 1975 \\
\hline Jim Bunning & 1955 & 1971 & Joe Niekro & 1967 & 2005 & Kevin Brown & 1986 & 2005 \\
\hline Jim Palmer & 1965 & 1984 & John Smoltz & 1988 & 2009 & Lefty Grove & 1925 & 1941 \\
\hline John Smoltz & 1988 & 2009 & Kevin Brown & 1986 & 2005 & Mike Mussina & 1991 & 2008 \\
\hline Juan Marichal & 1960 & 1975 & Mike Mussina & 1991 & 2008 & Mort Cooper & 1938 & 1949 \\
\hline Kevin Brown & 1986 & 2005 & Nolan Ryan & 1966 & 1993 & Pedro Martinez & 1992 & 2009 \\
\hline Mike Mussina & 1991 & 2008 & Orel Hershiser & 1983 & 2000 & Randy Johnson & 1988 & 2009 \\
\hline Mike Scott & 1979 & 1991 & Phil Niekro & 1964 & 1987 & Red Ruffing & 1924 & 1947 \\
\hline Nolan Ryan & 1966 & 1993 & Randy Johnson & 1988 & 2009 & Roger Clemens & 1984 & 2007 \\
\hline Pascual Perez & 1980 & 1991 & Rick Reuschel & 1972 & 1991 & Steve Rogers & 1973 & 1985 \\
\hline Pedro Martinez & 1992 & 2009 & Roger Clemens & 1984 & 2007 & Tom Glavine & 1987 & 2008 \\
\hline Randy Johnson & 1988 & 2009 & Steve Carlton & 1965 & 1988 & Tom Seaver & 1967 & 1986 \\
\hline Rich Gossage & 1972 & 1994 & Tom Glavine & 1987 & 2008 & Warren Spahn & 1942 & 1965 \\
\hline Robin Roberts & 1948 & 1966 & Tom Seaver & 1967 & 1986 & Whitey Ford & 1950 & 1967 \\
\hline Roger Clemens & 1984 & 2007 & Tommy John & 1963 & 1989 & & & \\
\hline Sandy Koufax & 1955 & 1966 & Vida Blue & 1969 & 1986 & & & \\
\hline Sid Fernandez & 1983 & 1997 & & & & & & \\
\hline Tom Seaver & 1967 & 1986 & & & & & & \\
\hline
\end{tabular}


Figure A.1. Peak Age Cohort ERA Career Trends
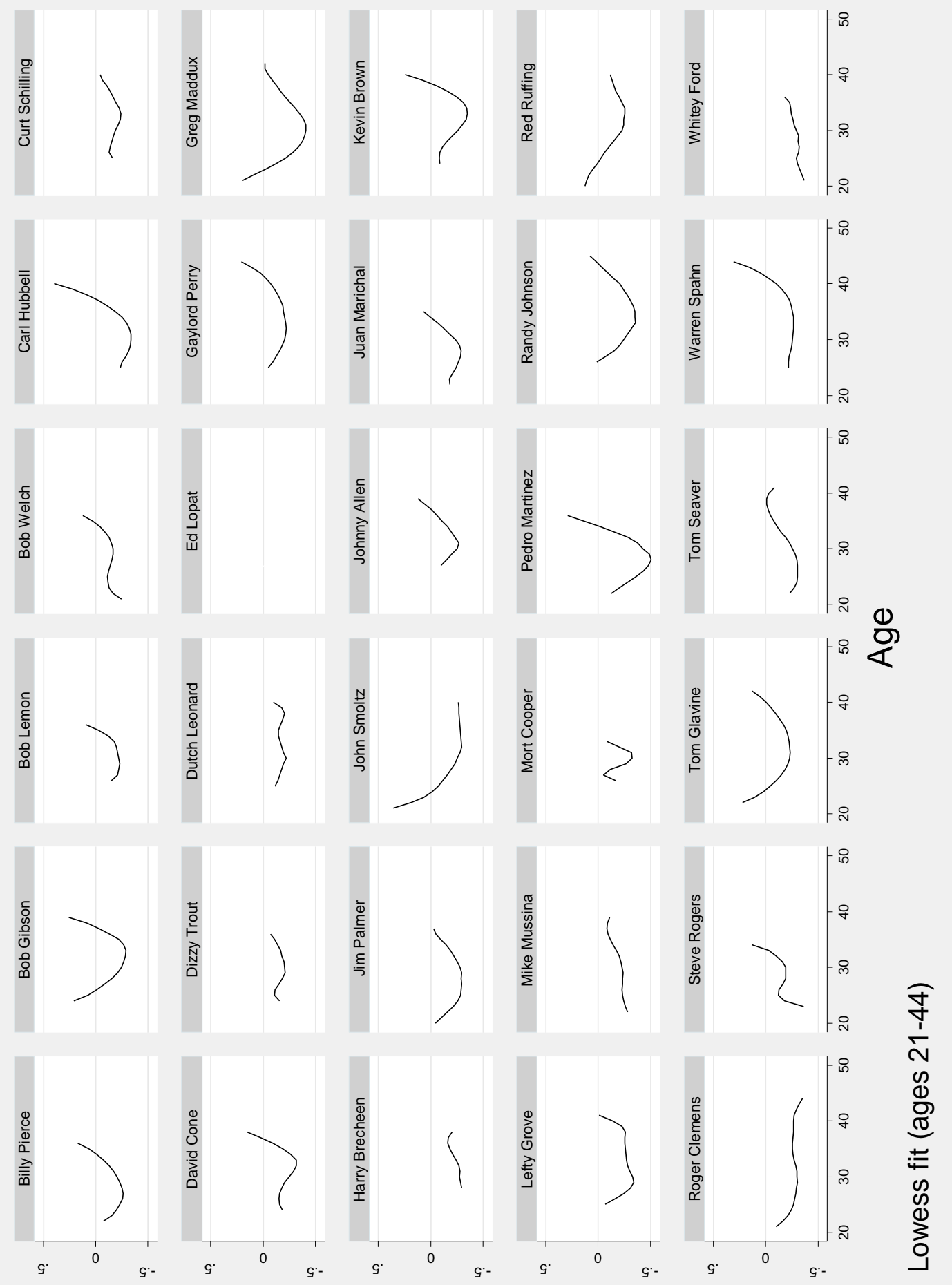
Figure A.2. Peak Age Cohort Strikeout Career Trends
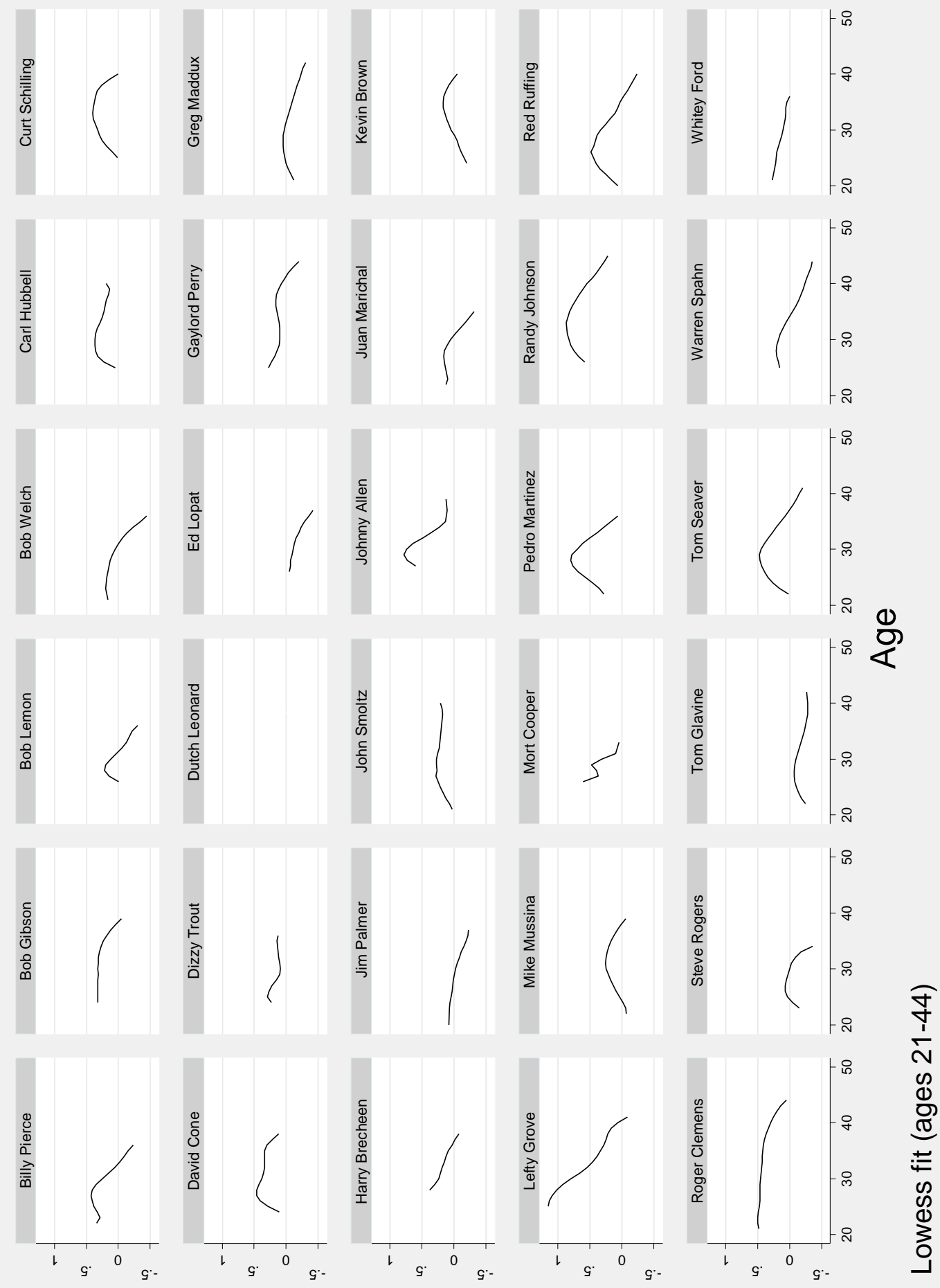
Figure A.3. Peak Age Cohort Walk Career Trends

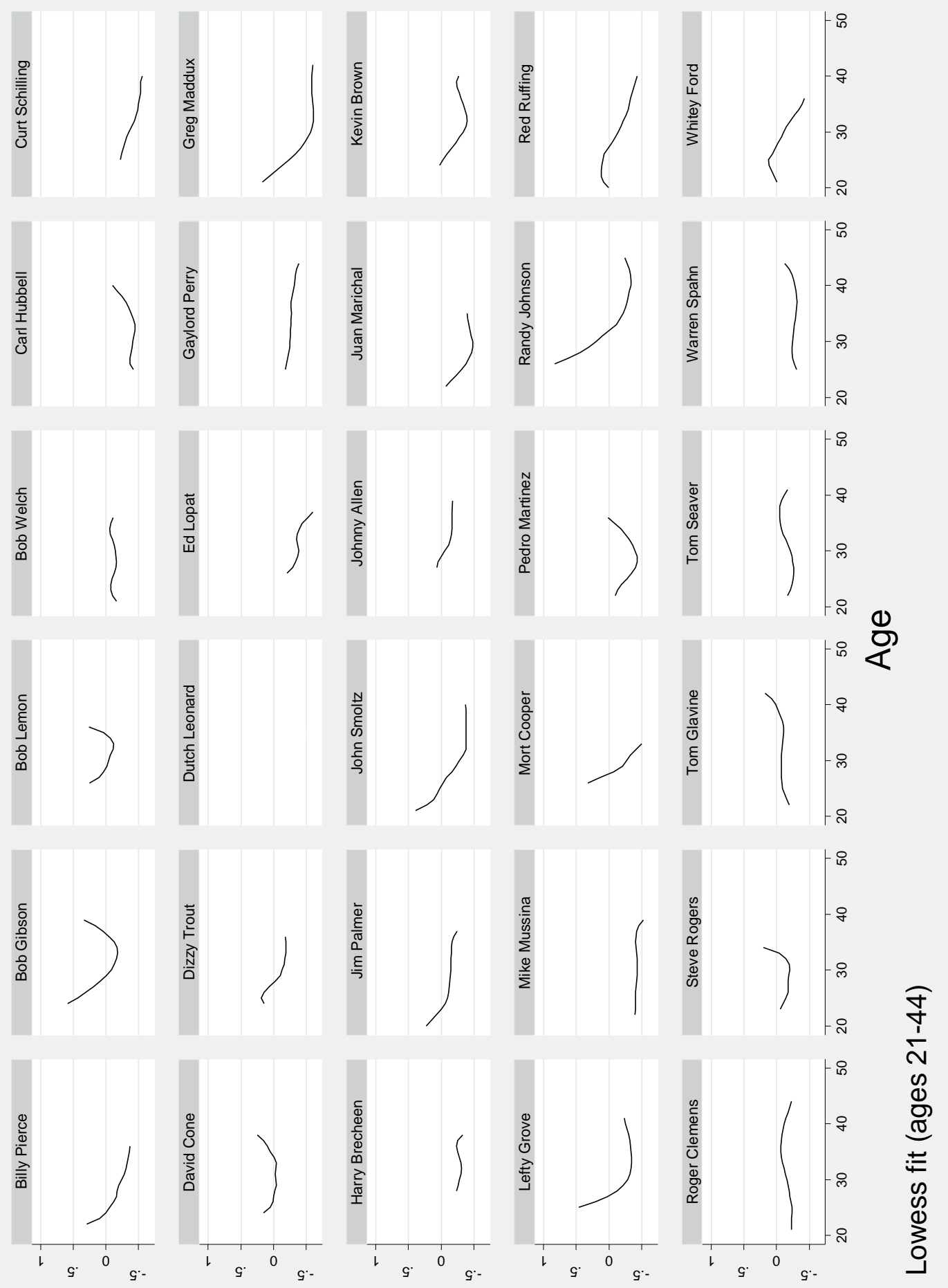


Figure A.4. Peak Age Cohort Home Run Career Trends
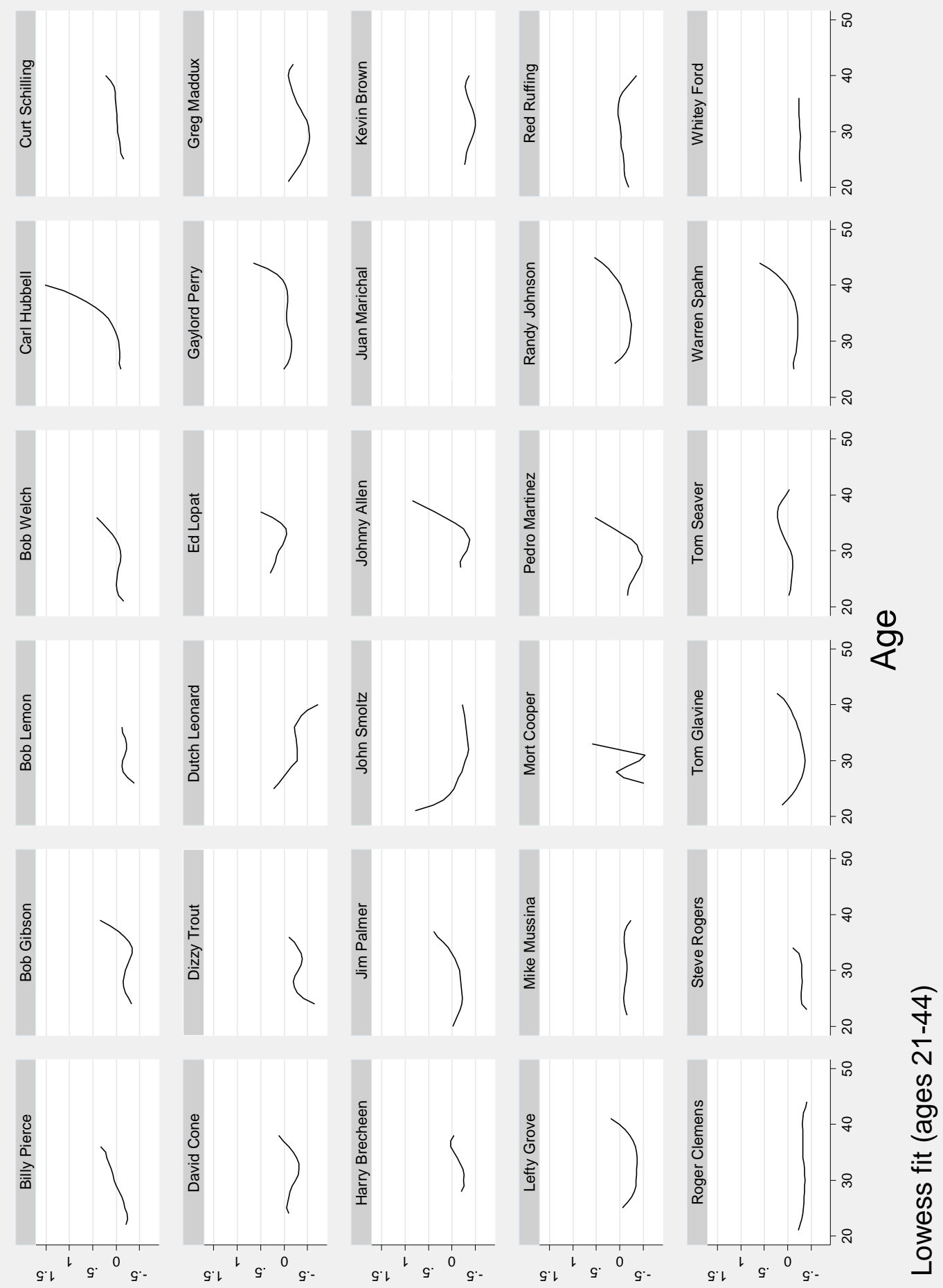